\title{
Rising inequality and trends in leisure
}

\author{
Timo Boppart ${ }^{1,2,4}$ (i) $\cdot$ L. Rachel Ngai ${ }^{3,4,5}$
}

Accepted: 6 March 2021 / Published online: 30 March 2021

(c) The Author(s) 2021

\begin{abstract}
This paper develops a model that generates rising average leisure time and increasing leisure inequality along a path of balanced growth. Households derive utility from three sources: market goods, home goods and leisure. Home production and leisure are both activities that require time and capital. Households allocate time and capital to these non-market activities and supply labor. The dynamics are driven by activity-specific TFP growth and a spread in the distribution of household-specific labor market efficiencies. When the spread is set to replicate the increase in wage inequality across education groups, the model can account for the observed average time series and cross-sectional dynamics of leisure time in the U.S. over the last five decades.
\end{abstract}

Keywords Leisure $\cdot$ Labor supply $\cdot$ Inequality $\cdot$ Home-production $\cdot$ Balanced growth path

JEL Classification $\mathrm{O} 41 \cdot \mathrm{J} 22 \cdot \mathrm{E} 24$

\section{Introduction}

The distribution in income, consumption and wealth has received a lot of attention in economics in order to make statements about economic welfare. Income, consumption, and wealth, however, are all related to an individual's market activity and ignore additional dimensions of heterogeneity outside the market place. ${ }^{1}$ In the U.S. there have been significant changes in the allocation of time of different educational groups outside the market

1 Boerma and Karabarbounis (2017, 2020) and Rachel (2019) are notable exceptions, where welfare is derived from a broader set of activities.

Timo Boppart

timo.boppart@iies.su.se

L. Rachel Ngai

L.ngai@1se.ac.uk

1 IIES, Stockholm University, Stockholm, Sweden

2 SIAW, University of St. Gallen, St. Gallen, Switzerland

3 London School of Economics, London, UK

4 CEPR, London, UK

5 CfM, London, UK 
place. Overall leisure time has been trending up but this aggregate trend masks heterogeneity across skill groups. Whereas leisure time was relatively equally distributed across educational groups half a century ago, nowadays low skilled individuals enjoy (on average) systematically more leisure time. This increase in leisure inequality is partially mirrored in hours worked across skill groups; hours worked of high-skilled individuals decrease slower than for low skilled individuals.

The main contribution of this paper is to provide a simple growth model that is consistent with both a rise in aggregate leisure and an increase in leisure inequality along a path of (exact) aggregate balanced growth. In our model individuals derive utility from market produced goods, home produced goods as well as leisure. There is rising wage inequality-modeled as exogenous changes in household-specific efficiency units-that drives the differential trends in hours. ${ }^{2}$ As the relative implicit price of leisure increases over time due to technical change there is a general upward trend in leisure time. This is the case because leisure and the composite of market and home goods enters the utility function as gross complements such that the income effect of a wage change dominates its substitution effect. Hence, in the aggregate time series rising wages are associated with rising average leisure time whereas the cross-sectional micro data shows that households who experienced a faster wage growth, i.e., households with higher education, had a slower increase in leisure time.

The key mechanism that allows us to square the two finding is intertemporal substitution of labor supplied to the market à la Lucas and Rapping (1969). Due to this intertemporal substitution, households who face a faster wage growth chose to raise leisure time more slowly, whereas in the aggregate time series households take more and more time off as the market productivity (and average wage) increases. Without intertemporal substitution of labor, a theory that matches the aggregate time series would also in the cross-section predict that a higher wage growth should be associated with faster rising leisure time. As a consequence without intertemporal leisure substitution the aggregate time series and crosssectional micro patterns cannot be squared.

The model economy consists of heterogeneous households with household-specific labor market efficiencies (per unit of time) and different levels of initial wealth. The distribution of labor market efficiencies can be interpreted as mapping into the distribution of educational qualifications. The household derives utility from the consumption of market goods, home goods and leisure goods. The key assumption is that high skilled households have a comparative advantage in the production of market goods as opposed to home and leisure goods. Market and home goods are gross substitutes with an elasticity of substitution higher than one (e.g., cooking at home vs. buying a take-away), but both are poor substitutes to leisure goods, with an elasticity of substitution less than one (as they are different type of goods, watching TV vs. having a haircut). Production of all three activities requires time and capital as inputs, and each activity has its own specific rate of TFP growth. In contrast to our approach, the literature typically models leisure time as directly generating utility. However, the majority of leisure time, such as watching TV, involves the usage of some capital (see table VII of Aguiar \& Hurst, 2007a). As shown in the representative

\footnotetext{
2 The rising wage inequality could be driven by skill-biased technological change (see Katz \& Murphy, 1992). See also Elsby and Shapiro (2012) who explain the rising inequality in employment rates between high and low skilled men through returns to experience.
} 
agent model in Ngai and Pissarides (2008), such a generalization allows for a trend in leisure along a path of balanced growth of the aggregate capital stock. ${ }^{3}$

The optimal time allocation is driven by the relative opportunity costs of the three activities market, home and leisure as well as the intertemporal substitution of hours supplied to the market. Both the activity-specific TFP growth common to all households and the household-specific change in market efficiency of time affects the relative implicit prices of the different activities. Faster TFP growth in the market leads to a rising relative implicit prices of leisure. Given that leisure and non-leisure goods are gross complements, this relative price effect leads to a common shift in the time allocation of all households toward leisure. On the other hand, the household-specific change in the market efficiency of time, i.e., wages, induces through intertemporal substitution a skill group-specific deviations from the common trends. The growth in the marginal utility of market consumption is pinned down by an Euler equation and is equalized across all households, whereas there is an incentive to adjust labor supply along the intertemporal margin, i.e., households have an incentive to work relatively hard in periods of high relative wages. Increasing wage inequality then implies that the more-educated households tend to work (relatively) longer hours in later years whereas less-educated household tend to rather frontload their working hours. This leads to less of an increase in leisure for the more-educated whereas leisure increases over this period even more for the less-educated. So put together, the model can account for both the time series and cross-sectional facts on time allocation. The theory also speaks to the timing; in the 60s and 70s, when wage inequality did not rise, there is no change along the intertemporal margin and the households are expected to increase their leisure time pari passu. The theory predicts a rise in leisure inequality only after the $80 \mathrm{~s}$ when wage rates systematically started to diverge across skill groups.

To quantitatively assess the mechanism, we calibrate the parameters of the model to match perfectly the fractions of time allocated to the three activities of four education groups in the U.S. in the year 1965. We then calibrate in our model changes in relative labor efficiency units of the different groups to replicate the observed change in relative wages. Together with the overall productivity growth the implied wages make predictions for the dynamics of the time allocation. The model successfully captures the parallel rise and the subsequent divergence in leisure shares across the four education groups. Overall, it does also a good job in accounting for the aggregate trend in leisure and the rise in leisure inequality. It accounts for all the rise in aggregate leisure and slightly over-predicts the rise in leisure inequality. We conclude from this quantification that a simple model with intertemporal labor substitution can account for the observed pattern in the data.

Consistent with the empirical work by Attanasio et al. (2015), our theory suggests that the rising leisure inequality needs to be taken into account together with the rising inequality in market outcomes in order to make welfare statements. Our paper contributes to this issue by developing a simple model to illustrate how increasing wage inequality itself can generate a rise in leisure inequality and partially mitigates the effect of wage inequality on welfare. This mitigating effect is also present in the calibrated model of Boerma and Karabarbounis (2020) based on expenditure and time-use data of the last two decades.

\footnotetext{
${ }^{3}$ Here it is important to define the aggregate capital stock to include household durables used for home production and leisure. See Boppart and Krusell (2020) for a theory that squares balanced growth with trends in leisure in a representative agent economy with a traditional preference formulation over leisure and consumption.
} 
In our theory, leisure production play an important role in squaring a trend in leisure time with an aggregate balanced growth path. This aspect is similar to Ngai and Pissarides (2008), which however abstracts from the cross-section facts. ${ }^{4}$ Leisure as an activity that not only involves time but also capital, plays a key role in Vandenbroucke (2009), Kopecky (2011) and Bridgman (2016b) too. ${ }^{5}$ These papers study also both time trends and cross-section facts, but their main mechanism is the falling relative price of leisure capital whereas we emphasize the higher productivity growth for market production. Vandenbroucke (2009) is motivated by the differential decline in market hours across different wage-group during the period 1900-1950 and consequently treats all non-market hours as leisure and abstracts from home production. Kopecky (2011) is motivated by the trend in retirement and focuses on time use across different age groups. In contrast to our paper, Bridgman (2016b) focuses on the quantitative role played by different capital intensities across market, home and leisure production where the main objective is to account for changes in the labor market wedge.

Finally, while most of macroeconomics models feature in the long-run constant hours worked and leisure time (see, e.g., Cooley \& Prescott, 1995), Boppart and Krusell (2020) propose a general class of utility functions defined over consumption and leisure to obtain trends in aggregate market hours and aggregate leisure along a balanced growth path. ${ }^{6}$ In contrast, we obtain these trends by explicitly modeling leisure and home production. As home production is a closer substitute to market good than leisure this distinction matters for welfare. Furthermore, our explicit goal in this paper is to replicate the cross-section facts on leisure and market hours. Finally, our theory that models leisure and home production explicitly as a process involving time and capital makes additional predictions about, e.g., the relative growth of leisure durables relative to the aggregate capital stock.

The paper is organized as follows. The next section document the empirical facts in U.S. data that motivate the paper. In Sect. 2 we present a growth model with heterogeneous households and derives its balanced growth path. Section 4 shows that the balanced growth path of the model is consistent with a rise in leisure in the aggregate time series together with a rise in leisure inequality in the cross-section. Section 5 presents the quantitative results. Finally, Sect. 6 concludes.

\section{Empirical facts}

Aguiar and Hurst (2007a) document a growing inequality in leisure that mirrors the rising inequality in wages and expenditures between 1965 to 2003. Figure 1a report the "rise in leisure inequality" across educational groups, where we updated the data series in Aguiar

\footnotetext{
${ }^{4}$ Our objective to develop a growth model that allows for dynamics of cross-section facts with an aggregated balanced growth path is similar to Caselli and Ventura (2000) who, however, do not study the allocation of time.

${ }^{5}$ See also the recent paper by Aguiar et al. (2017) that focuses on leisure "luxuries" and how innovation in video gaming and other recreational computer activities have induced young men to shift their time allocation from market to leisure activities since 2004. Rachel (2019) shows the role of leisure-enhancing technologies, such as free TV channels or smartphone apps, on the trend in hours worked and productivity growth.

${ }^{6}$ See also Boppart et al. (2017) that looks at the intensive and extensive margin of labor supply separately and Rachel (2019) who studies endogenous leisure technologies along an asymptotic balanced growth path of falling hours worked.
} 
and Hurst (2007a) to 2013. ${ }^{7}$ Individuals with less than 12 years of education experienced a rise in leisure time over the past half century of slightly more than $8 \mathrm{~h}$ per week while for college graduates the increase in leisure is less than $1 \mathrm{~h}$ per week. ${ }^{8}$ The data also shows an overall upward trend in leisure time. Over the period 1965-2013 weekly leisure time increased on average by $4.5 \mathrm{~h}$ (see Fig. 1b). ${ }^{9}$ This is a substantial increase, especially when viewed in the context of average time work in the market of 33-37 h per week over the same period. ${ }^{10}$ In a representative agent framework with a Cobb-Douglas production function and a capital share of $1 / 3$, a simple back-of-the-envelope calculation suggests that if the additional leisure time of $4.5 \mathrm{~h}$ were instead used to increase labor input, output would be boosted by $8.5 \%(4.5 / 35$ multiplied by $2 / 3){ }^{11}$

In Fig. 1, leisure is directly measured and not just a residual category after subtracting hours worked from a fixed total time budget. Time used data for "home production" is relevant to obtain a full picture of time allocation and this separate category will be considered in our theory as well. The decline in home hours is indeed quantitatively important to account for the increase in leisure for the less educated and the increase in market hours for the more educated post $1985 .{ }^{12}$ However, Fig. $1 \mathrm{~b}$ clearly shows that the rise in leisure inequality is accompanied by rising inequality (and a slight downward trend) in market work. It is mainly the group with less than 12 years of education that reduced hours worked.

Figure 2 reports the wage of each education group relative to the average wage. ${ }^{13}$ Starting in the 80 s there was a systematic rise in wage inequality across the education groups. The timing of the change in wage inequality corresponds to the ones found in time allocation in Fig. 1a, b. Until the 80s when wages grew at roughly the same rate there is no divergence of leisure time or hours worked across the different education groups. The rising inequality in the time allocation only starts at around the same time as wages between high and low skilled workers start to diverge. ${ }^{14}$ This is supportive evidence for our theoretical mechanism that is based on intertemporal substitution of leisure and hours worked due

\footnotetext{
7 The time use data is constructed according to the methodology in Aguiar and Hurst (2007a) and the numbers are reported in Table O.1 in the "Online Appendix". Throughout the paper leisure refers to Aguiar and Hurst's measure "Leisure Measure 1" which includes time spent on socializing, in passive leisure, in active leisure, volunteering, in pet care and gardening.

${ }^{8}$ A similar rise in leisure inequality has also been documented for seven other OECD countries using Multinational Time Use Study for the period 1970s to 2000s by Gimenez-Nadal and Sevilla (2012). See Ramey and Francis (2009) for patterns of leisure in the U.S. prior to 1965.

9 It is important to note that these findings are adjusted for changes in demographic compositions in age, sex and presence of child. By fixing the demographic weights, the findings reflect how time spent in a given activities change over time instead of changes in demographic composition within a specific group.

10 See also Winston (1966) and Bick et al. (2018) who document a similar negative relationship between hours worked and the level of development across countries.

11 Note that this number only captures the static effect, that holds the capital stock constant, whereas the dynamic effect would be even larger.

12 Following Aguiar and Hurst (2007a), child care is excluded. Total childcare time has been stable over time and similar across education groups in the time-use surveys between 1965-1993 at around $3 \mathrm{~h}$ per week but it experienced a substantial rise of 2-3 h during the 2000s. Ramey and Ramey (2010) argue that this rise is due to increased competition for college admission.

13 As in Fig. 1, we follow Aguiar and Hurst (2007a) methodology to control for changes in demographic composition. Due to data constraint, we cannot control for whether a child is presence, thus we have 40 demographic cells instead of 72 demographic cells.

14 Using the same time use data, Fang and Zhu (2017) also documented a positive correlation between wage rates and market hours and the negative correlation between wage rates and home hours and leisure in the cross section. Using data for 1890s, 1973 and 1991, Costa (2000) documented a similar trend that market hours for low-wage workers have declined relative to high-wage workers.
} 


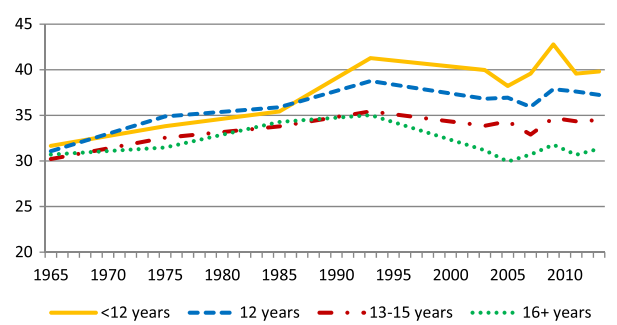

(a) Leisure hours

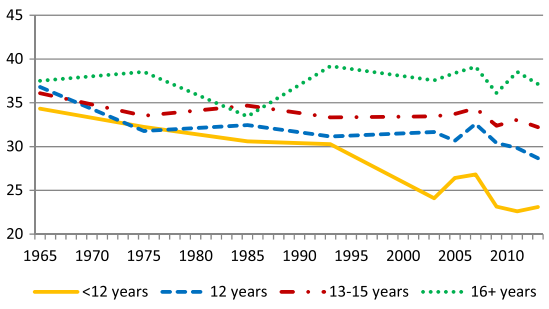

(b) Market hours

Fig. 1 Leisure and market hours by education group. Notes: The figure plots leisure time and market hours 1965-2013 for four education groups. Source: 1965-1966 America's Use of Time; 1975-1976 Time Use in Economics and Social Accounts; 1985 Americans' Use of Time; 1992-1994 National Human Activity Pattern Survey; and 2003-2009 American Time Use Surveys. The data is adjusted for changes in demographic composition: age, sex and presence of child, following Aguiar and Hurst (2007a) methodology. Leisure refers to Leisure Measure 1 in Aguiar and Hurst (2007a), which includes leisure activities such as socializing, watching $\mathrm{TV}$, reading etc.

to differential wage growth. We will show in the next section that a simple model with activity-specific technical change common to all households, household specific changes in labor market efficiencies and intertemporal substitution of labor can replicate both the parallel rise in leisure time prior to 1985 and its subsequent divergence. In our theory the falling trend in home hours is due to the lower productivity growth for home goods relative to market goods, a process of marketization (Freeman \& Schettkat, 2005). ${ }^{15}$

Before we turn to the theory, let us discuss some potential data issues. Aguiar and Hurst (2009) show that the increase in leisure inequality is particularly strong for men. Since there has been a relative decline in the employment rate of less educated men, one natural question is whether the decline in market hours is not involuntary. Aguiar and Hurst's answer is no, as they find that trends in employment status explain less than half of the increase in the leisure gap between less-educated (those with 12 years of education or less) and more-educated men (those with more than 12 years of education). They conclude that most of the increase in leisure gap is driven by labor supply and not due to either an increase in involuntary unemployment or disability and this is also the approach we take in this paper. However, it is important to note that adjustment along the extensive margin are an important driver of the trends seen in Fig. 1 b. ${ }^{16}$

Ramey (2007) shows that the sharp increase in average leisure time in the time used survey is somewhat sensitive to the categorization—but that the rise in leisure "inequality" is robust. What about hours worked? Do other dataset than the time use survey show the same empirical pattern in hours worked as we documented here? Figure O.2 in the "Online Appendix" shows the pattern in hours worked for the four skill groups in the CPS data. Overall the (average) decline in hours worked is less pronounced but the divergence in time allocation is clearly

\footnotetext{
${ }^{15}$ Using personal consumption expenditure data, Bridgman (2016a) shows a substantial rise in purchased services as a share of total (home plus market) services. See also Mazzolari and Ragusa (2013) who document how a rise in the skill premium can affect the demand for unskilled services through marketization.

16 In Figure O.1 and Table O.2 in the "Online Appendix" we show the trends in leisure time across education groups for males and females separately. The diverging pattern in leisure time can can be found for both men and women, suggesting that the trends are not driven by changing specialization within the household.
} 


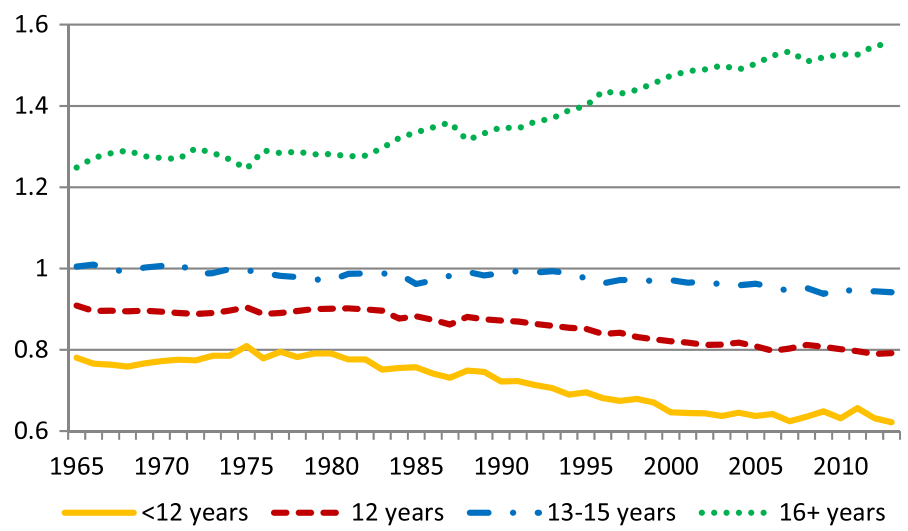

Fig. 2 Wage relative to average wage by education group. Notes: The figure plots wage relative average wage 1965-2013 for four education groups. Source: CPS/March samples. Non-farm working individuals aged 21-65 who are not student. Adjusted for changes in demographic compositions in age and sex, following the methodology of Aguiar and Hurst (2007a)

visible too, although the timing is slightly different. Unlike, e.g., the Census data [see Michelacci and Pijoan-Mas (2016) and Wolcott (2021) for men] the CPS data suggests the diverging trend stopped in the early 90s. In this paper we focus on the time used survey data (and Aguiar $\&$ Hurst's, 2007a definition) mainly because it allows us to split non-working time further up into leisure and home production. We acknowledge that the the trends in hours worked do differ between the CPS and time use data in terms of timing and quantitative size. It is beyond the scope of this paper to resolve this issue. Qualitatively at least, the main empirical motivation of rising inequality in leisure time and hours worked indeed seems to be a robust finding.

\section{Theory}

\subsection{Household side}

\subsubsection{Preferences, skill and budget constraint}

There is a unit interval of heterogeneous households $i \in[0,1]$ with the following preferences

$$
\mathcal{U}_{i}(0)=\sum_{i=0}^{\infty} \beta^{t} u\left(c_{m, i}(t), c_{h, i}(t), c_{z, i}(t)\right)
$$

where $u(\cdot)$ is the instantaneous utility function defined over three different components, a market good, $c_{m, i}$, a home produced good, $c_{h, i}$, and leisure, $c_{z, i}$. The discount factor is denoted by $\beta<1$. The instantaneous utility function is assumed to take the following nested CES form

$$
u(\cdot)=\frac{\varepsilon}{\varepsilon-1} \log \left[\omega_{i}\left[\psi c_{m, i}(t)^{\frac{\sigma-1}{\sigma}}+(1-\psi) c_{h, i}(t)^{\frac{\sigma-1}{\sigma}}\right]^{\frac{\sigma(\varepsilon-1)}{(\sigma-1) \varepsilon}}+\left(1-\omega_{i}\right) c_{z, i}(t)^{\frac{\varepsilon-1}{\varepsilon}}\right] .
$$


The parameter $\sigma>0$ controls the elasticity of substitution between market goods and home production. The elasticity of substitution between leisure and the CES consumption bundle consisting of market goods and home production is given by $\varepsilon>0$. $\psi$ is the weight on market goods within the consumption bundle, while $1-\omega_{i} \in(0,1)$ is the weight on leisure, which we allow to be household specific. ${ }^{17}$ Household $i$ is endowed with $a_{i}(0)$ units of initial capital which she can either rent out (and get a market rental rate $R(t)$ ) or use in home production, $k_{h, i}$, or in leisure production, $k_{z, i}$. Each household has $\bar{l}$ units of time that can be either supplied to the labor market, $l_{m, i}$, or allocated to home production, $l_{h, i}$, or leisure $l_{z, i}$. The time constraint thus reads

$$
\bar{l}=l_{m, i}(t)+l_{h, i}(t)+l_{z, i}(t), \forall i, t .
$$

Each unit of time supplied to the labor market is rewarded by a household specific wage rate $w_{i}(t)$. Differences in $w_{i}(t)$ across households depend on the household-specific market efficiency per unit of time, $e_{i}(t)>0$. The efficiency $e_{i}(t)$ follows an exogenous process satisfying the following two assumptions.

Assumption $1 \int_{0}^{1} e_{i}(t) d i=\bar{e}, \forall t$

Assumption $2 \lim _{t \rightarrow \infty} e_{i}(t)=\hat{e}_{i}, \forall i$.

Assumption 1 states that the mean of $e_{i}(t)$ is constant over time and Assumption 2 makes sure that the $e_{i}(t)$ terms converges to a stationary distribution. ${ }^{18}$ In the market place, the efficiency-adjusted labor input of household $i$ that supplies $l_{m, i}(t)$ time units to the labor market is given by $e_{i}(t) l_{m, i}(t)$. We denote the aggregate available efficiency-adjusted labor input in the economy by $L$, i.e.,

$$
L \equiv \int_{0}^{1} e_{i}(t)\left[l_{m, i}(t)+l_{h, i}(t)+l_{z, i}(t)\right] d i=\bar{l} \bar{e}, \forall t .
$$

Since $e_{i}(t)$ augments the hourly labor input, $l_{m, i}(t)$, proportionally, perfect competitive labor markets allow us to write the household-specific (hourly) wage rate as

$$
w_{i}(t)=\bar{w}(t) e_{i}(t)
$$

where $\bar{w}(t)=\int_{0}^{1} w_{i}(t) d i$ is average wage rate per efficiency unit or the wage rate of a household with average skill, i.e., $e_{i}(t)=\bar{e}$. Equation (3) highlights that individual wage rates can change over time for two different reasons: (i) through $\bar{w}(t)$ changes due to aggregate dynamics common to all households like technological change or capital deepening, or (ii) through changes in the household-specific efficiency term $e_{i}(t)$. One interpretation of $e_{i}(t)$ dynamics is that a household $i$ has an intrinsic ability to achieve certain education level. Then, the attained education is considered as fixed but the return to an education level $e_{i}(t)$ is changing over time. This is a reduced form modeling that allows us to match the empirically observed increases in the wage dispersion as shown in Fig. 2. The changes in

\footnotetext{
17 The heterogeneity in this weight allows us to match perfectly in our quantitative section the initial time allocation of all the groups.

18 Assumption 1 excludes changes in average skill over time. However, given the Cobb-Douglas technologies we will impose later on, a growing average skill is mathematically identical to a change in the rate of technological change in the market place.
} 
$e_{i}(t)$ should be understood as summarizing effects of labor demand on the skill premium as skill-biased technological change or trade competition. As $\bar{w}(t)$ is both the average wage and the wage of a household with $\bar{e}$, the data shown in Fig. 2 suggests that the household with $\bar{e}$ can be interpreted as the group with 13-15 years of education as its wage almost exactly tracks the average rate. As will be shown later, the theory predicts a monotonic rise in leisure for this group, which is consistent with the data presented in Fig. 1a.

There is a single market good that can be consumed or invested. The price of the market good is normalized to one in all points in time. Finally, we assume a constant depreciation rate, $\delta$. Then, household $i$ faces the following budget constraint

$$
a_{i}(t+1)=R(t)\left[a_{i}(t)-k_{h, i}(t)-k_{z, i}(t)\right]+a_{i}(t)[1-\delta]+\left[\bar{l}-l_{h, i}(t)-l_{z, i}(t)\right] w_{i}(t)-c_{m, i}(t) .
$$

Households are heterogeneous because they differ in their initial wealth $a_{i}(0)$ as well as in their (return to) skill $\left\{e_{i}(t)\right\}_{t=0}^{\infty}$.

\subsubsection{Leisure and home production}

Both time, $l_{z, i}(t)$, and capital (i.e., leisure durables), $k_{z, i}(t)$, is required to generate the leisure output that enters utility $c_{z, i}(t)$. We assume for this leisure output a Cobb-Douglas structure

$$
c_{z, i}(t)=k_{z, i}(t)^{\alpha} l_{z, i}(t)^{1-\alpha} .
$$

Home production takes the following functional form

$$
c_{h, i}(t)=k_{h, i}(t)^{\alpha}\left[A_{h}(t) l_{h, i}(t)\right]^{1-\alpha},
$$

where $k_{h, i}(t)$ is used capital (i.e., home durables), $l_{h, i}(t)$ is time used for home production, and $A_{h}(t)=A_{h}(0) \gamma_{h}^{t}$ is a Harrod-neutral technology term in home production with a gross rate of technological progress $\gamma_{h}>1$.

\subsubsection{Households' problem}

Each household $i \in[0,1]$ maximizes (1) with respect to

$$
\left\{a_{i}(t+1), c_{m, i}(t), c_{h, i}(t), c_{z, i}(t), k_{h, i}(t), k_{z, i}(t), l_{h, i}(t), l_{z, i}(t)\right\}_{t=0}^{\infty}
$$

subject to (4), (5) and (6) as well as a standard no-Ponzi game condition that can be expressed as

$$
\lim _{T \rightarrow \infty}\left[a_{i}(T+1) \prod_{s=1}^{T} \frac{1}{1+R(s)-\delta}\right] \geq 0 .
$$

The initial wealth, $a_{i}(0)$, and $\left\{e_{i}(t)\right\}_{t=0}^{\infty}$ are exogenously given. 


\subsection{Production side}

\subsubsection{Technology}

The market good is produced under perfect competition by a representative firm with the following technology

$$
Y(t)=K_{m}(t)^{\alpha}\left[A_{m}(t) L_{m}(t)\right]^{1-\alpha},
$$

where $Y(t)$ is aggregate market output, $K_{m}(t)$ is the aggregate capital stock used in the market economy and $L_{m}(t)$ is the total skill-adjusted labor input. The term $A_{m}(t)=A_{m}(0) \gamma_{m}^{t}$, with $\gamma_{m}>1$, captures exogenous Harrod-neutral technical progress in the market place.

\subsubsection{Firm's problem}

The representative firm minimizes production cost of a given output level, $Y(t)$, where the firm takes the rental rate, $R(t)$, and the wage per skill-adjusted labor input, $\bar{w}(t)$, as given.

\subsection{Market clearing}

Market clearing on the capital and labor market requires

$$
\int_{0}^{1}\left[a_{i}(t)-k_{h, i}(t)-k_{z, i}(t)\right] d i=K_{m}(t),
$$

and

$$
\int_{0}^{1} l_{m, i}(t) e_{i}(t) d i=L_{m}(t) .
$$

The resource constraint is given by

$$
Y(t)=\int_{0}^{1} c_{m, i}(t) d i+\int_{0}^{1}\left(a_{i}(t+1)-(1-\delta) a_{i}(t)\right) d i,
$$

where the left-hand side is total output and the right-hand side is total market good consumption plus total (gross) investment.

\subsection{Equilibrium definition}

In this economy a dynamic equilibrium is defined as follows.

Definition 1 A dynamic equilibrium is a sequence of time and capital allocation

$$
\left\{l_{m, i}(t), l_{h, i}(t), l_{z, i}(t), k_{m, i}(t), k_{h, i}(t), k_{z, i}(t)\right\}_{t=0}^{\infty}, \forall i,
$$

a sequence of wealth and market, home production and leisure consumption and 


$$
\left\{a_{i}(t), c_{m, i}(t), c_{h, i}(t), c_{z, i}(t)\right\}_{t=0}^{\infty}, \forall i
$$

a sequence of the aggregate capital stock and skill-adjusted labor used in the market economy $\left\{K_{m}(t), L_{m}(t)\right\}_{t=0}^{\infty}$, and a sequence of rental and wage rates $\left\{R(t), \bar{w}(t), w_{i}(t)\right\}_{t=0}^{\infty}, \forall i$, that is jointly solving the households' problem (as specified in Sect. 3.1.3), the firm's problem (as specified in Sect. 3.2.2) and is as well consistent with the market clearing conditions (9)-(11).

\subsection{Equilibrium path}

A formal characterization of the households' and firm's problem and the derivation of the first-order conditions can be found in "Appendix 1". In the following, we present the equilibrium in two steps: First, we characterize the equilibrium time and capital allocation across market, home and leisure. Second, we present the dynamic equilibrium conditions and show the existence of a balanced growth path, where the return to capital, $R$, is constant.

\subsubsection{Intratemporal equilibrium}

We define the aggregate capital stock in the economy (including household and leisure durables) as $K(t) \equiv \int_{0}^{1} a_{i}(t) d i$. The potential market income of household $i$ (by renting out all the capital, and supplying all her time to the labor market) is given by

$$
y_{i}(t) \equiv R(t) a_{i}(t)+\bar{l} w_{i}(t) .
$$

We define the difference between this potential market income and (gross) savings as total implicit consumption expenditure

$$
c_{i}(t) \equiv y_{i}(t)-\left[a_{i}(t+1)-(1-\delta) a_{i}(t)\right] .
$$

The variables $y_{i}(t)$ and $c_{i}(t)$ do not have a directly observable empirical counter-part. Nevertheless, it is helpful to introduce them to illustrates how they relate to the dynamics in the standard neoclassical growth model. In the following we show that, given the path of $c_{i}(t)$, the static equilibrium can fully be characterized. Describing the equilibrium dynamics of $c_{i}(t)$ will then be the subject of the next section.

The first-order conditions of the households' and firm's problem imply the following equilibrium conditions.

Lemma 1 Optimal capital intensities of the households and the representative firm require

$$
\frac{k_{h, i}(t)}{e_{i}(t) l_{h, i}(t)}=\frac{k_{z, i}(t)}{e_{i}(t) l_{z, i}(t)}=\frac{K_{m}(t)}{L_{m}(t)}=\frac{K(t)}{L} .
$$

The first-order conditions of the firm's problem combined with the market clearing conditions yield 


$$
\bar{w}(t)=(1-\alpha) A_{m}(t)\left[\frac{K(t)}{A_{m}(t) L}\right]^{\alpha},
$$

and

$$
R(t)=\alpha\left[\frac{K(t)}{A_{m}(t) L}\right]^{\alpha-1} .
$$

See "Appendix 1" for a proof.

The results of Lemma 1 are due to free mobility of time and physical capital, which equalize the marginal rate of technical substitution in the production of market output, home and leisure. Together with the Cobb-Douglas technologies with identical output elasticities of labor, this implies identical capital intensities across all three activities for any given household. Note however that the capital intensity will differ across households because the labor efficiency is not identical. More explicitly, household with higher market efficiency, $e_{i}$, use more capital per unit of time for home and leisure production relative to the household with lower market efficiency. ${ }^{19}$ Finally, the equalization of capital intensities across activities allows us to express the marginal return to labor and capital as a function of the aggregate capital per efficiency units of labor (see (15) and (16)).

In order to gain an intuition for the optimal allocation of time across market, home, and leisure it is useful to introduce implicit prices (i.e., implicit marginal cost) for $c_{h, i}$ and $c_{z, i}$

$$
p_{h, i}(t) \equiv\left[\frac{w_{i}(t)}{(1-\alpha) A_{h}(t)}\right]^{1-\alpha}\left[\frac{R(t)}{\alpha}\right]^{\alpha},
$$

and

$$
p_{z, i}(t) \equiv\left[\frac{w_{i}(t)}{1-\alpha}\right]^{1-\alpha}\left[\frac{R(t)}{\alpha}\right]^{\alpha} .
$$

Given our choice of the market price as a numéraire, we have

$$
p_{m}(t)=1=\left[\frac{\bar{w}(t)}{(1-\alpha) A_{m}(t)}\right]^{1-\alpha}\left[\frac{R(t)}{\alpha}\right]^{\alpha} .
$$

Because the opportunity cost of time differs across households with different skills the implicit price of home production and leisure is household specific. For the relative implicit prices we get the following lemma.

Lemma 2 In equilibrium, the implicit prices (relative to the market price) are given by

$$
p_{h, i}(t)=\left(\frac{A_{m}(t) e_{i}(t)}{A_{h}(t)}\right)^{1-\alpha},
$$

and

\footnotetext{
19 This is in line with the empirical pattern documented by Fang et al. (2020) for the four education groups using expenditure data from Consumer Expenditure Survey (CEX) and American Time Use Survey for 2003-2014.
} 


$$
p_{z, i}(t)=\left[A_{m}(t) e_{i}(t)\right]^{1-\alpha}
$$

The relative implicit price between leisure and home is given by

$$
\frac{p_{z, i}(t)}{p_{h, i}(t)}=A_{h}(t)^{1-\alpha} \text {. }
$$

Proof The expression for the relative prices follow immediately from (17)-(19) and (3).

Given the identical output elasticities of labor across activities, all the relative implicit costs can be expressed independently of the factor prices. As lower-skilled households have a comparative advantage in home and leisure the implicit relative prices of these activities are lower for households with a lower $e_{i}(t)$. In contrast the relative prices of home to leisure are the same across households. ${ }^{20}$ Relative prices not only vary in the cross-section but also over time, due to the differences in the pace of technological progress across activities. Together with the definitions in Eqs. (12) and (13), we obtain the next lemma.

Lemma 3 In equilibrium, we have

$$
y_{i}(t)=(1-\alpha) A_{m}(t)\left[\frac{K(t)}{A_{m}(t) L}\right]^{\alpha} e_{i}(t) \bar{l}+\alpha\left[\frac{K(t)}{A_{m}(t) L}\right]^{\alpha-1} a_{i}(t),
$$

and

$$
c_{i}(t)=c_{m, i}(t)+c_{h, i}(t) p_{h, i}(t)+c_{z, i}(t) p_{z, i}(t) .
$$

Proof Equation (23) follows immediately from combining (3), (12), (15), and (16). Equation (24) follows from (3), (4), (14), (15), and (16) as well as the definition in (17).

Lemma 3 states that the potential income $y_{i}(t)$ is higher for household with higher labor efficiency units $e_{i}(t)$ and higher wealth $a_{i}(t)$. The variable $c_{i}(t)$ can be expressed as the total implicit consumption expenditure of household $i$ for market, home, and leisure goods.

In the following we define $\tilde{p}_{m h, i}(t) \equiv\left[\psi^{\sigma}+(1-\psi)^{\sigma} p_{h, i}(t)^{1-\sigma}\right]^{\frac{1}{1-\sigma}}$ as the implicit composite price for non-leisure goods. Note that this implicit price is household specific since the labor market efficiency unit $e_{i}$ differs in the cross-section. Moreover, we define the implicit expenditure shares of leisure and home as $x_{j, i}(t) \equiv \frac{c_{j, i}(t) p_{j, i}(t)}{c_{i}(t)}, j=z, h$. Lemmas 2 and 3 together imply the following lemma.

Lemma 4 In equilibrium, the implicit expenditure shares of leisure and home are

$$
x_{z, i}(t)=\frac{1}{1+\left(\frac{\omega_{i}}{1-\omega_{i}}\right)^{\varepsilon}\left(\frac{\tilde{p}_{m h, i}(t)}{p_{z, i}(t)}\right)^{1-\varepsilon}},
$$

and

\footnotetext{
${ }^{20}$ This can be generalized by allowing higher skilled household to have a relative comparative advantage in home production compared to leisure. Such a generalization however would not change the main results in this paper.
} 


$$
x_{h, i}(t)=\frac{1-x_{z, i}(t)}{1+\left(\frac{\psi}{1-\psi}\right)^{\sigma} p_{h, i}^{\sigma-1}(t)} .
$$

See "Appendix 1" for a proof.

For a given path of $c_{i}(t)$ and implicit prices $p_{h, i}(t)$ and $p_{z, i}(t)$, Lemma 4 contains closed form solutions for the equilibrium quantities of $c_{z, i}(t), c_{m, i}(t)$, and $c_{h, i}(t)$.

Note that because of the (homothetic) CES structure these implicit expenditure shares are only functions of relative implicit prices, which are given in terms of exogenous technology terms in Lemma 2. Hence, together with the expressions for the relative implicit prices closed from solutions for the consumed quantities of market goods, home production, and leisure are obtained for any given $c_{i}(t)$. Combining the quantities in Lemma 4 with the production functions (5) and (6) and the optimality condition in production (14) allows us to express the allocation of production factors to the different activities in the following proposition.

Proposition 1 Leisure and home production time is given by

$$
l_{j, i}(t)=x_{j, i}(t) \frac{c_{i}(t)}{A_{m}(t) e_{i}(t)\left[\frac{K(t)}{A_{m}(t) L}\right]^{\alpha}}, j=z, h .
$$

Capital used in leisure and home production is given by

$$
k_{j, i}(t)=x_{j, i}(t) c_{i}(t)\left[\frac{K(t)}{A_{m}(t) L}\right]^{1-\alpha}, j=z, h .
$$

Proof The allocation of the different production factors are simply obtained by combining the quantities in Lemma 4 with the production functions (5) and (6) and the optimality condition in production (14).

The remaining variables then follow immediately as for instance $l_{m, i}(t)=\bar{l}-l_{h, i}(t)-l_{z, i}(t)$. This illustrates that for a given distribution of $c_{i}(t), \forall i$ and a given aggregate capital stock $K(t)$ we obtain closed form solution for all equilibrium variables. To fully solve the model we analyze the equilibrium path of $K(t)$ and $c_{i}(t)$ in the next section. To prepare the analysis in the cross-section and over time it is helpful to express the time of leisure relative to home production in equilibrium. This is done in the next lemma.

Lemma 5 The relative time (and capital) used for leisure relative to home production is given by

$$
\frac{l_{z, i}(t)}{l_{h, i}(t)}=\frac{k_{z, i}(t)}{k_{h, i}(t)}=(1-\psi)^{\frac{\sigma(1-\varepsilon)}{\sigma-1}}\left(\frac{1-\omega_{i}}{\omega_{i}}\right)^{\varepsilon}\left(\frac{p_{z, i}(t)}{p_{h, i}(t)}\right)^{1-\varepsilon}\left(1+\left(\frac{\psi}{1-\psi}\right)^{\sigma} p_{h, i}(t)^{\sigma-1}\right)^{\frac{\sigma-\varepsilon}{\sigma-1}} .
$$

Proof First, note that according to (27) we have $\frac{l_{z, i}(t)}{l_{h, i}(t)}=\frac{x_{z, i}(t)}{x_{h, i}(t)}$. Substituting in the values of Lemma 4 (see (25) and (26)) gives 


$$
\frac{l_{z, i}(t)}{l_{h, i}(t)}=\left(\frac{1-\omega_{i}}{\omega_{i}}\right)^{\varepsilon}\left(\frac{\tilde{p}_{m h, i}(t)}{p_{z, i}(t)}\right)^{\varepsilon-1}\left(1+\left(\frac{\psi}{1-\psi}\right)^{\sigma} p_{h, i}(t)^{\sigma-1}\right) .
$$

Using the definition of $\tilde{p}_{m h, i}(t)$ allows us to rewrite this expression as (29). Finally, note that (14) implies that the capital intensities equalize between the activities home production and leisure.

It is important to emphasize again that - as seen in Lemma 2-the relative implicit cost of a unit of home service/goods as well as leisure depends on both the technologies $A_{m}(t)$ and $A_{h}(t)$ as well as $e_{i}(t)$ and the heterogeneous preference weights. Consequently, the relative implicit costs vary over time and across households (with different $e_{i}(t)$ and preferences). Hence, the composition of consumed market goods, home production and leisure differs in the cross-section. For the same reason the allocation of time changes over time and differs in the cross-section too.

\subsubsection{Intertemporal equilibrium}

This section describes the equilibrium dynamics of the household wealth and consumption, $a_{i}(t)$ and $c_{i}(t)$ by characterizing a household's optimal saving behavior. This is done in the next lemma.

Lemma 6 The first-order conditions of the household problem imply

$$
a_{i}(t+1)=a_{i}(t)[1+R(t)-\delta]+\bar{l} e_{i}(t) \bar{w}(t)-c_{i}(t), \forall i,
$$

and

$$
c_{i}(t+1)=\beta[1+R(t+1)-\delta] c_{i}(t), \forall i .
$$

For a given path of factor prices, (30) and (31) characterize a system of difference equations in $a_{i}(t)$ and $c_{i}(t)$, where $a_{i}(0)$ is exogenously given and there is the transversality condition

$$
\lim _{T \rightarrow \infty}\left[a_{i}(T+1) \prod_{s=1}^{T} \frac{1}{1+R(s)-\delta}\right]=0 .
$$

The aggregate wealth, $K(t)$, and factor prices $w(t)$ and $R(t)$ then follow immediately from the dynamics of household wealth (see Lemma 1). Finally, $y_{i}(t)$ follows from the individual budget (23).

\subsection{Balanced growth path}

Definition 2 A balanced growth path is defined as an equilibrium path along which aggregate wealth/capital, $K(t)$, and the wage rate, $\bar{w}(t)$, grow at a constant rate and the rental and real interest rate are constant.

The detrended capital stock is denoted by $\tilde{k}(t) \equiv \frac{K(t)}{A_{m}(t) L}$. The following proposition holds. 
Proposition 2 There exists a unique globally saddle path stable balanced growth path with $\tilde{k}^{\star}=\left[\frac{\alpha}{\gamma_{m} / \beta-1+\delta}\right]^{\frac{1}{1-\alpha}}$.

See "Appendix 1" for a proof.

It is worth noting that despite the trends in the time allocation, the model admits an exact balanced growth path, i.e., a balanced growth path that exists for a finite capital stock and not only asymptotically. Along the balanced growth path, i.e., with $\tilde{k}(0)=\tilde{k}^{\star}$, implicit consumption $c_{i}(t)$ of all households and the aggregate capital stock grow a constant rate $\gamma_{m}$, or formally

$$
\frac{c_{i}(t+1)}{c_{i}(t)}=\frac{\int_{0}^{1} c_{i}(t+1) d i}{\int_{0}^{1} c_{i}(t) d i}=\frac{\int_{0}^{1} a_{i}(t+1) d i}{\int_{0}^{1} a_{i}(t) d i}=\frac{K(t+1)}{K(t)}=\gamma_{m}, \forall i .
$$

The wage rate is given by

$$
\bar{w}(t)=\bar{w}(t)^{\star}=(1-\alpha) A_{m}(t)\left(\tilde{k}^{\star}\right)^{\alpha},
$$

and grows at the same rate $\gamma_{m}$. The rental rate is constant and given by

$$
R(t)=R^{\star}=\alpha\left(\tilde{k}^{\star}\right)^{\alpha-1} .
$$

For the existence of the exact balanced growth path it is important to remember that the definition of the aggregate capital stock includes household and leisure durables. Explicitly modeling home and leisure production as activities that require capital (i.e., household and leisure durables) is therefore important. Along the balanced growth path implicit consumption $c_{i}(t)$ grows at a constant rate but market consumption does not necessarily. The initial level, $c_{i}(0)$ is pinned down by the transversality condition, as shown in the following lemma.

Lemma 7 Along the balanced growth path, the initial implicit consumption expenditure level is given by

$$
c_{i}(0)=\left[1+R^{\star}-\delta-\gamma_{m}\right] a_{i}(0)+\sum_{t=0}^{\infty} \frac{\bar{w}(0)^{\star} e_{i}(t) \bar{l}\left[1+R^{\star}-\delta-\gamma_{m}\right]}{1+R^{\star}-\delta}\left(\frac{\gamma_{m}}{1+R^{\star}-\delta}\right)^{t} .
$$

See "Appendix 1" for a proof.

This lemma shows that only the permanent income pins down the initial consumption level $c_{i}(0)$. Thus, the entire consumption path, $c_{i}(t)$, of all household is know. Other equilibrium variables such as the households' time allocation and capital allocation follow directly from the intratemporal optimality conditions (see Sect. 3.5.1).

The dynamics of $K(t), \bar{w}(t)$ and $R(t)$ along the balanced growth path are standard. The model predicts that the real output per hour $\frac{Y(t)}{\int_{0}^{1} l_{m, i}(t) d i}$ and the real capital stock (including 
the stock of consumption durables) $K(t)$ both grow at constant gross rate $\gamma_{m}$. The former follows from the assumption that $\int_{0}^{1} e_{i}(t) d i$ is constant over time (see Assumption 1). ${ }^{21}$ The other implications of balanced growth are a constant growth rate of the average wage and a constant rental and interest rate.

As in Ngai and Pissarides (2007), the existence of an exact balanced growth path relies on the assumption of unitary intertemporal elasticity of substitution and identical output elasticities of labor across the three activities.

Although the model admits an aggregate balanced growth path, there does not exist a representative agent in this framework: In the data the wage of the group with 13-15 years of education is about the same as the average wage (suggesting that this is a group with roughly average skill $\bar{e}$ ). ${ }^{22}$ Despite this the theory does not imply nor require that the time allocation of this group follows the average time allocation in the economy. This result follows directly from the equilibrium time allocation in (27), which is non-linear in $e_{i}(t)$.

As $e_{i}(t)$ might vary over time, the growth rates of $y_{i}(t)$ and wealth $a_{i}(t)$ are none-constant, even along the balanced growth path. Moreover, both the time allocation and the consumption structure exhibits rich dynamics across households along the balanced growth path. Changes in the consumption structure and time allocation are driven by changes in the household-specific relative implicit prices (see Lemma 4). These relative implicit prices change due to differences in the TFP growth rates across activities (controlled by $\gamma_{m}$ and $\left.\gamma_{h}\right)$ and due to household-specific changes in labor efficiency $e_{i}(t)$. How changes in the relative implicit prices affect the consumption structure depends crucially on the elasticities of substitution across activities controlled by the parameters $\varepsilon$ and $\sigma$. In order to focus on the empirically case, we next make specific assumptions about the parameters $\gamma_{m}, \gamma_{h}, \varepsilon$ and $\sigma$ and then characterize the equilibrium dynamics.

Equations (33)-(35) described the equilibrium dynamics along the balanced growth path. The transitional dynamics of this economy in terms of $K(t), R(t), w(t)$ and $c_{i}(t)$ are identical to the one in the standard neoclassical growth model. ${ }^{23}$ Finally, the asymptotic equilibrium of the economy is formally characterized in Proposition O.1 in the "Online Appendix O.1".

\section{Time allocation along the balanced growth path}

In the following we focus on an economy that is along its balanced growth path, i.e., we assume $\tilde{k}(0)=\tilde{k}^{\star}$. Furthermore, we make the following assumption about the parameters $\gamma_{m}, \gamma_{h}, \varepsilon$ and $\sigma$.

Assumption $3 \gamma_{m}>\gamma_{h}>1$ and $\sigma>1>\varepsilon$.

The elasticity between home and market goods being larger than one is supported by empirical findings (see the survey article by Aguiar et al., 2012). Among others, Blundell

\footnotetext{
${ }^{21}$ Figure O.3 in "Online Appendix O.1" shows the real capital stock per-capita in the U.S. (where the capital stock includes as in the theory the stock of consumer durables). On a logarithmic scale this series is indeed very well approximated by a linear time trend.

22 See Table O.1 in the "Online Appendix O.1".

${ }^{23}$ In general, unless $\delta=1$, no closed form solution exists for the transitional dynamics.
} 
and Walker (1982) and Ham and Reilly (2002) present evidence for complementarity between consumption goods and leisure.

In the following we discuss the joint dynamics of the allocation of time and capital under Assumption 3 both in the cross-section as well as over time. This is done in two steps. First, we discuss the dynamics under the assumption that the $e_{i}(t)$ distribution is held fixed. The theoretical results are then compared to the data of the period 1965-1985, that was characterized by little change in wage inequality. Second, we allow for changing market efficiencies and discuss how it can explain the observed divergence in leisure time since the 80 s.

\subsection{Equilibrium dynamics with constant efficiency terms $e_{i}$}

Analyzing the balanced growth path under the assumption of stationary $e_{i}$ terms gives the following lemma.

Lemma 8 For constant efficiency terms $\left\{e_{i}\right\}_{i=0}^{1}$, the leisure hours relative to home production hours, $\frac{l_{z, i}(t)}{l_{h, i}(t)}$, are monotonically increasing over time for all household $i$.

Proof The equilibrium expression for $\frac{l_{z, i}(t)}{l_{h, i}(t)}$ is given in Lemma 5. For a constant $e_{i}$ and with $\gamma_{m}>\gamma_{h}, p_{h, i}(t)$ and $\frac{p_{z, i}(t)}{p_{h, i}(t)}$ are monotonically increasing over time (see (20) and (22)). Hence, with $\sigma>1>\varepsilon, \frac{l_{z, i}(t)}{l_{h, i}(t)}$ is monotonically increasing over time for all $i$.

Lemma 8 implies that leisure hours relative to home production hours increase monotonically for households with a constant $e_{i}$. This prediction is confirmed in Fig. 4 that shows a parallel rise in $\frac{l_{z, i}(t)}{l_{h, i}(t)}$ over the period 1965-1985 which was characterized by pari passu wage growth. Furthermore, for the groups with 13-15 years of education (which is roughly the empirical counterpart of a household with constant $e_{i}=\bar{e}$ ) these relative hours increase monotonically through the whole sample period. The intuition for the theoretical result is the following: Since the labor market efficiency terms, $e_{i}$, are constant, the changes in time spent for the different activities are entirely explained by the relative implicit price movements. As the labor intensities are identical across activities the price changes are entirely driven by the rates of technical change. The implications of the relative implicit price changes are determined by the (nested) CES preferences of households. With $\gamma_{m}>\gamma_{h}$ the (implicit) price of leisure increases relative to home production as well as relative to the market good (and consequently also relative to the market-home composite). With an elasticity of substitution between leisure and the market-home composite being smaller then one, the implicit expenditure share of leisure (and time allocated to leisure) increases, whereas time allocated to home production decreases.

Lemma 8 also suggests that the average stock of leisure relative to household durables should monotonically increase over time. Figure 3 shows that this was indeed the case. ${ }^{24}$

The equilibrium dynamics of leisure hours are derived in the next lemma.

Lemma 9 For constant efficiency terms $\left\{e_{i}\right\}_{i=0}^{1}$, we have along the balanced growth path

\footnotetext{
${ }^{24}$ Figure O.4 in "Online Appendix O.1" show a very similar trend in the ratio of leisure durables relative to household durables in terms of investments.
} 


$$
\frac{l_{z, i}(t+1)}{l_{z, i}(t)}=\frac{x_{z, i}(t+1)}{x_{z, i}(t)}>1, \forall i
$$

Hence, leisure hours are growing monotonically over time for all households.

Proof With a constant $e_{i}$, the equality in (37) follows immediately from (27) and the fact that $c_{i}(t)$ grows at gross rate $\gamma_{m}$ and that $\frac{K(t)}{A_{m}(t) L}=k^{\star}$ along the balanced growth path. Now $x_{z, i}(t)$ is given by (25) and is an decreasing function of $\frac{\tilde{p}_{m h, i}(t)}{p_{z, i}(t)}$ since $\varepsilon<1$. The relative price is given by

$$
\frac{\tilde{p}_{m h, i}(t)}{p_{z, i}(t)}=\left[\psi^{\sigma}\left[A_{m}(t) e_{i}(t)\right]^{-(1-\alpha)(1-\sigma)}+(1-\psi)^{\sigma} A_{h}(t)^{-(1-\alpha)(1-\sigma)}\right]^{\frac{1}{1-\sigma}} .
$$

With a stationary $e_{i}$ distribution, the gross growth rate of $\frac{\tilde{p}_{m h, i}(t)}{p_{z, i}(t)}$ is a weighted geometric mean of the gross growth factors $\gamma_{m}^{-(1-\alpha)}<1$ and $\gamma_{h}^{-(1-\alpha)}<1$. Hence, we have

$$
\gamma_{\tilde{p}_{m h, i}}(t) / \gamma_{p_{z, i}}(t) \equiv \frac{\tilde{p}_{m h, i}(t+1)}{\tilde{p}_{m h, i}(t)} \frac{p_{z, i}(t)}{p_{z, i}(t+1)}<1, \forall i .
$$

Consequently, $x_{z, i}(t)$ and $l_{z, i}(t)$ are monotonically increasing over time for all $i$.

Lemma 9 establishes that we expect to see in periods of a stationary wage distribution monotonically increasing leisure hours for all educational groups. The period 1965-1985 reflects no clear trend in wage inequality (see Fig. 2) and leisure hours were indeed monotonically increasing for all educational groups over this period (see Fig. 1). The intuition for this theoretical result is again as above and hinges on $\gamma_{m}>\gamma_{h}>1$ and the assumption that leisure and the home-market composite are gross complements (see Assumption 3).

So far we analyzed the case with a stationary wage distribution. We next consider the case of diverging $e_{i}$ terms and compare the theoretical prediction with the post-1985 period, which was characterized by rising wage inequality.

\subsection{Equilibrium dynamics with changing efficiency terms $e_{i}$}

In this section we analyze the equilibrium dynamics with systematic changes in the $e_{i}$ terms. The purpose of these shifts in the $e_{i}$ terms is to generate the steep increase in wage inequality since the $80 \mathrm{~s}$. As it can be seen from (27) changes in the efficiency term $e_{i}$ will affect the time allocation. Let the gross growth factor of $e_{i}$ for household $i$ be denoted as $\gamma_{e_{i}}(t) \equiv \frac{e_{i}(t+1)}{e_{i}(t)}$. We obtain the following proposition.

Proposition 3 Along the balanced growth path, the gross growth rate of leisure $\frac{l_{z, i}(t+1)}{l_{z, i}(t)}$ is a decreasing function of $\gamma_{e_{i}}(t)$.

Proof With a changing $e_{i}(t)$ term, given $c_{i}(t)$ grows at gross rate $\gamma_{m}$ and capital per efficiency units of labor is constant along the balanced growth path, (27) implies 


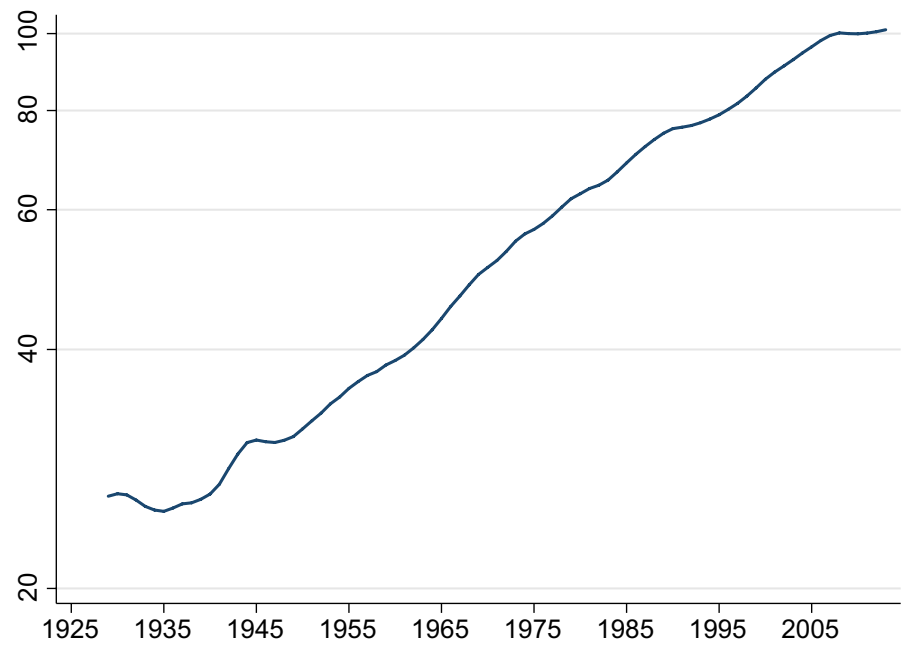

Fig. 3 Stock of leisure durables relative to household durables. Notes: The figure plots aggregate "recreational" durable goods relative to aggregate "furnishing and household durables" corresponding to $\frac{\int_{0}^{1} k_{z, i}(t) d i}{\int_{0}^{1} k_{h, i}(t) d i}$ in the model. Source: BEA table 8.1

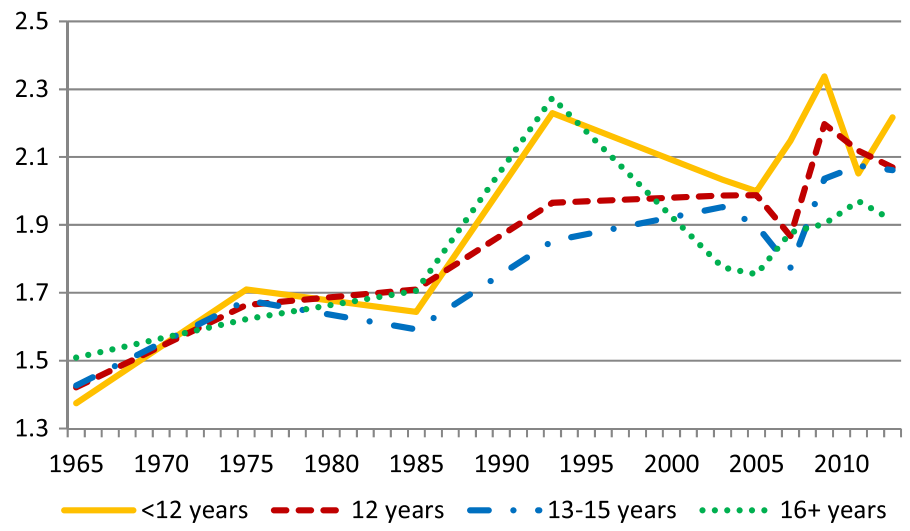

Fig. 4 Leisure hours relative to home production hours. Notes: Source: Time use surveys. Following Aguiar and Hurst (2007a) methodology, individuals aged 21-65 who are not student nor retired. Childcare is excluded from home production and leisure refers to Leisure Measure 1 in Aguiar and Hurst (2007a)

$$
\frac{l_{z, i}(t+1)}{l_{z, i}(t)}=\frac{x_{z, i}(t+1)}{x_{z, i}(t)} \gamma_{e_{i}}(t)^{-1}, \forall i .
$$

The term $x_{z, i}(t)$ is given by (25) and we can express it as

$$
\frac{x_{z, i}(t)}{x_{z, i}(t+1)}=x_{z, i}(t)+\left(1-x_{z, i}(t)\right)\left[\gamma_{\tilde{p}_{m h, i}}(t) / \gamma_{p_{z, i}}(t)\right]^{1-\varepsilon} \text {. }
$$

Combining (40) with (41) gives 


$$
\frac{l_{z, i}(t)}{l_{z, i}(t+1)}=x_{z, i}(t) \gamma_{e_{i}}(t)+\left(1-x_{z, i}(t)\right)\left[\gamma_{\tilde{p}_{m h, i}}(t) / \gamma_{p_{z, i}}(t)\right]^{1-\varepsilon} \gamma_{e_{i}}(t) .
$$

The term $\frac{\tilde{p}_{m h, i}(t)}{p_{z, i}(t)}$ is given in (38). Consequently, the gowth factor of this relative price is a weighted geometric average of $\left[\gamma_{m} \gamma_{e_{i}}(t)\right]^{-(1-\alpha)}$ and $\gamma_{h}^{-(1-\alpha)}<1$, or formally

$$
\gamma_{\tilde{p}_{m h, i}}(t) / \gamma_{p_{z, i}}(t)=\left[\xi\left[e_{i}(t)\right]\left[\gamma_{m} \gamma_{e_{i}}(t)\right]^{-(1-\alpha)(1-\sigma)}+\left\{1-\xi\left[e_{i}(t)\right]\right\} \gamma_{h}^{-(1-\alpha)(1-\sigma)}\right]^{\frac{1}{1-\sigma}},
$$

where the weight $\xi\left[e_{i}(t)\right]$, which depends on the level of $e_{i}(t)$ but is independent of its growth rate, is given by

$$
\xi\left[e_{i}(t)\right] \equiv \frac{\psi_{i}^{\sigma}\left[A_{m}(t) e_{i}(t)\right]^{(1-\alpha)(\sigma-1)}}{\psi^{\sigma}\left[A_{m}(t) e_{i}(t)\right]^{(1-\alpha)(\sigma-1)}+(1-\psi)^{\sigma} A_{h}(t)^{(1-\alpha)(\sigma-1)}} .
$$

Combining (42) and (43) gives

$$
\frac{l_{z, i}(t)}{l_{z, i}(t+1)}=x_{z, i}(t) \gamma_{e_{i}}(t)+\left(1-x_{z, i}(t)\right) \phi\left[e_{i}(t), \gamma_{e_{i}}(t)\right]
$$

with

$$
\phi[\cdot]=\left[\xi[\cdot] \gamma_{e_{i}}^{(1-\sigma)\left[\frac{\varepsilon}{1-\varepsilon}+\alpha\right]} \gamma_{m}(t)^{-(1-\alpha)(1-\sigma)}+\{1-\xi[\cdot]\} \gamma_{e_{i}}(t)^{\frac{1-\sigma}{1-\varepsilon}} \gamma_{h}^{-(1-\alpha)(1-\sigma)}\right]^{\frac{1-\varepsilon}{1-\sigma}}
$$

It follows that $\phi\left[e_{i}(t), \gamma_{e_{i}}(t)\right]$ is strictly increasing in $\gamma_{e_{i}}$ since we have $\sigma>1>\varepsilon$. Consequently, in view of (45), $\frac{l_{z, i}(t)}{l_{z, i}(t+1)}$ is monotonically increasing and $\frac{l_{z, i}(t+1)}{l_{z, i}(t)}$ decreasing in $\gamma_{e_{i}}$.

The intuition behind this result is the following: along the balanced growth path, the growth of $c_{i}(t)$ is identical across households and independent of the changes in $e_{i}(t)$. Hence, what matters for the dynamics of $l_{z}$ is the change in the implicit share spent on leisure $x_{z, i}(t)$. The dynamics of this implicit expenditure share depend on the changes in the implicit prices and the elasticities of substitution as discussed above. The implicit relative prices change due to the differences in technological change across activities and this effect is the same for all households. However, the changes in the $e_{i}$ terms affect additionally the relative implicit prices in a household-specific way. For households with an increasing $e_{i}$ the relative price of leisure increases at a faster rate which increases the implicit share spent on leisure even further. In a static model this would capture the whole effect and household with an increasing $e_{i}(t)$ term would therefore have an additional incentive to increase leisure hours. Hence, a static framework would not be able to generate both rising leisure inequality and generally rising leisure hours at the same time. In our model however, there is an additional direct effect of changes in $e_{i}(t)$ through intertemporal labor substitution (see (27)). A household that experiences a (steeper) growth in $e_{i}(t)$ will react by increasing the labor supply to the market and reduce leisure and this intertemporal effect will dominate. Hence, the model can replicate that households who experience a steeper wage growth will increase leisure by less (or even decrease it) whereas the fall in hours worked is particularly pronounced for households with falling relative wages. As highlighted in the introduction this is 
exactly what we observed in the U.S. after 1985. This pattern is summarize in the next proposition.

Proposition 4 For educational groups with $1 \geq \gamma_{e_{i}}(t)$, hours of leisure are increasing over time. For educational groups with $\gamma_{e_{i}}(t)>1$ leisure hours can be falling over time.

Proof We already showed that the growth rate of $l_{z, i}(t)$ is strictly falling in $\gamma_{e_{i}}(t)$ (see Proposition 3) and that the leisure growth is positive for $\gamma_{e_{i}}=1$ (see Lemma 9). Hence, leisure growth must be positive for $1 \geq \gamma_{e_{i}}(t)$. For the second statement, note that $\gamma_{\tilde{p}_{m h, i}}(t) / \gamma_{p_{z, i}}(t)$ is monotonically decreasing in $\gamma_{e_{i}}$ (see 43) and for $\gamma_{e_{i}} \gamma_{m} \geq \gamma_{h}$ we can even have $\gamma_{\tilde{p}_{m h, i}}(t) / \gamma_{p_{z, i}}(t) \leq 1$. This shows that $x_{z, i}(t)$ (and $l_{z}$ ) may fall for households who experience a sharp increase in $e_{i}$.

\section{Rising leisure inequality in the U.S., 1965-2013}

To quantitatively assess the role of the increase in wage dispersion in generating the rising leisure inequality, we calibrate the model parameters to match time allocation in 1965 in the U.S. for the four education groups. We feed in exogenous changes in the $e_{i}$ terms to replicate the time series of wages in Fig. 2 and then compare the predicted dynamics of time allocation to the data.

\subsection{Calibration}

The main object of interest is the time allocation or hour shares $l_{j, i} / \bar{l}$, for market $j=m$, home $j=h$ and leisure $j=z$. These shares sum by definition up to one. The parameters we need to calibrate to predict hour shares include elasticity parameters $\{\varepsilon, \sigma\}$, preference parameters $\left\{\beta, \psi, \omega_{i}\right\}$, technology parameters $\left\{\alpha, \delta, A_{m}(0), A_{h}(0), \gamma_{m}, \gamma_{h}\right\}$ and the household-specific market efficiency $e_{i}(t)$ for each of the four education groups.

The initial productivity $A_{m}(0)$ and $A_{h}(0)$ are normalized to one where $\{\beta, \delta, \alpha\}$ are set to the standard values in the macro literature. More specifically, the discount factor $\beta$ is set to 0.97 , the depreciation rate $\delta$ to 0.05 , and the capital share $\alpha$ is assumed to be 0.3 . There is an extensive literature summarized by Aguiar et al. (2012) providing estimates ranging from 1.5 to 2.5 for the elasticity of substitution between home and market consumption. ${ }^{25}$ We use the lower limit of these estimates and set $\sigma$ to 1.5. Regarding the elasticity of substitution between leisure and the home-market composite $\varepsilon$, there is no readily available estimate. However, Blundell and Walker (1982) and Ham and Reilly (2002) present evidence for complementarity between consumption and leisure, we therefore set $\varepsilon$ to 0.1 as the baseline parameter. Finally, the labor-augmenting productivity growth for market production, $\gamma_{m}$ is set to 1.02 which corresponds to a 2 percent growth in per-capita terms; while $\gamma_{h}$ for home production is set to 1.01 , which is in line with the estimate in Bridgman (2016a).

The remaining parameters $\left\{\psi, \omega_{i}, e_{i}(0)\right\}$ are model-specific. They are set to match the hours shares in 1965 for each of the four education group. The hour shares predicted by the

\footnotetext{
${ }^{25}$ See for example, Rupert et al. (1995), Aguiar and Hurst (2007b), Gelber and Mitchell (2012), and Fang and Zhu (2017).
} 


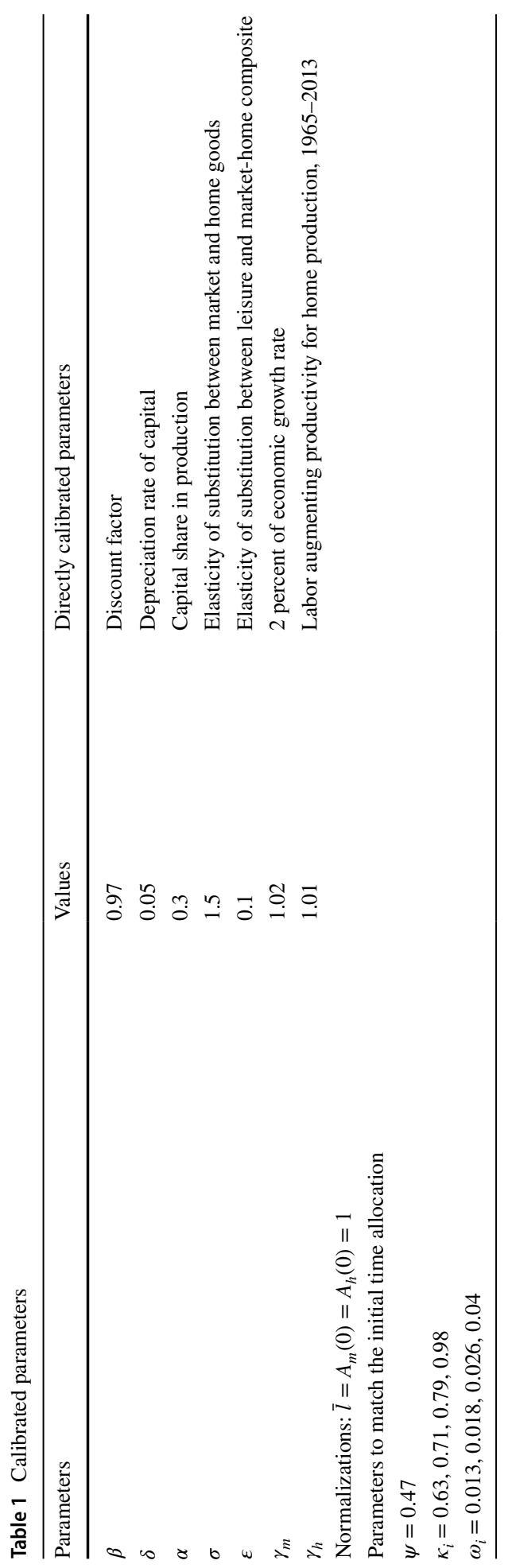


model are derived in Proposition 1, and reported in (27). Along the balanced growth path, both $c_{i}(t)$ and $K(t)$ grow at the gross rate $\gamma_{m}$, and the hour shares allocated to home and leisure satisfy

$$
l_{j, i}(t)=x_{j, i}(t)\left(\frac{\kappa_{i}}{e_{i}(t)}\right) ; \quad j=h, z ; \quad \kappa_{i} \equiv \frac{c_{i}(0)}{A_{m}(0)\left(\tilde{k}^{\star}\right)^{\alpha}},
$$

where $\kappa_{i}$ is a constant, $\tilde{k}^{\star}$ is derived in Proposition 2 and the initial consumption $c_{i}(0)$ is derived in (36). As explained previously, given the wage of the group with 13-15 years of education is almost exactly the same as the average, see Fig. 2, this group is taken as the $\bar{e}$ household. We can then calibrate $\psi=0.47$ to match the relative time allocation between home and market in 1965 for this group with 13-15 years of education. Given (3), the market efficiency $e_{i}(0)$ for the other three groups are then picked to match relative wages in the data in 1965 . The value of $\tilde{k}^{\star}$ is known given the parameters $\left\{\alpha, \beta, \delta, \gamma_{m}\right\}$, however, the value of $c_{i}(0)$ depends on the initial wealth and future wages. Instead of making assumptions about the initial wealth distribution and the asymptotic distribution of market efficiency $e_{i}$, there is a simpler way to directly calibrate $\kappa_{i}$. The implied values for $\kappa_{i}$ are $(0.63$, $0.71,0.79,0.98)$. Finally, given these values, we pick $\omega_{i}$ to match the share of leisure hours in total hours in 1965 for all groups. This implies the values $(0.013,0.018,0.026,0.04){ }^{26}$

Table 1 summarizes once again the calibrated parameter values. Note that the calibration only targets cross-sectional time allocation in 1965. Given the calibrated parameters, the dynamics of the time allocation for each education groups are implied by the time path of household-specific market efficiency, $e_{i}(t)$. We finally calibrate the trends in these efficiency terms over time to match the relative wages in Fig. 2 using Eq. (3). ${ }^{27}$

\subsection{Quantitative results}

Figure 5 show the predicted hour shares in leisure against the data. Let us first focus on the group with 13-15 years of education, which is the group with constant efficiency $\bar{e}$. For this group the dynamics of time allocation are entirely driven by activity-specific rates of technical change and therefore becomes very smooth. The rise in leisure share for this group is entirely driven by the low substitutability between leisure and (home and market) consumption $(\varepsilon<1)$ and the faster productivity growth of the market-home composite $\left(\min \left\{\gamma_{m}, \gamma_{h}\right\}>1\right)$. Quantitatively, the simple model does a good job at predicting the monotone rise in the leisure share for this group with 13-15 years of education: the theory predicts an increase from 0.35 in 1965 , to 0.38 in 1985 and 0.43 in 2013, whereas the share is in the data 0.38 and 0.41 in 1985 and 2013 , respectively. ${ }^{28}$ The theory also generates realistic changes in market and home shares. ${ }^{29}$ The model predicts for the group

\footnotetext{
26 "Online Appendix O.1.2" provides more detail how we arrive at these values for $\kappa_{i}$ and $\omega_{i}$.

27 Note that for the low skilled group the $e_{i}$ term is shrinking over time to fit the decline in the relative wage for this group. However, as the is also a general upward trend in wages due to technical change the calibration implies in absolute terms slightly increasing real wages even for the group with $<12$ years of education.

28 Note that the values in 1965 are matched by construction for all the hours shares.

${ }^{29}$ Figures O.5 and O.6 in the "Online Appendix" reports the predictions and compares it to the data.
} 
with 13-15 years of education a slight decline of market hours share from 0.41 in 1965 to 0.40 in 1985 and then to 0.39 in 2013; in line with the data where it decreases to 0.39 in 1985 and stays around the same level throughout. In terms of the hours share in home, the model's fit of the data is slightly worse for the group with 13-15 years of education. The model predicts a monotone decline from 0.24 in 1965 to 0.18 in 2013, whereas it was first roughly flat in the data and only started to decline after 1985 and fell to 0.20 in 2013. Still, given that the constant sector-specific productivity growth rates are the only driver of the changes for this group with 13-15 years of education, the predictions are matching the data fairly well.

Let us next turn to the prediction for the other education groups, where the labor efficiency terms are changing over time to match the group-specific evolution of wages. With changing wages the additional motive to intertemporally substitute the working effort kicks in; mainly after the 80 s when wages start to diverge. Table 2 summarizes the predicted changes in leisure and market shares over the first (1965-1985) and second (1985-2013) subperiod of the sample and compares them to the data. ${ }^{30}$ The model overall replicates remarkably well the parallel rise and the subsequent divergence in leisure time across education groups. Quantitatively, the theory predicts for the group with $<12$ years of education a significant acceleration in the rise in leisure share from $+4.3 \mathrm{ppt} 1965-1985$ to $+9.6 \mathrm{ppt} 1985-2013$. This compares to $+4.9 \mathrm{ppt}$ and $+9.2 \mathrm{ppt}$ in the data. For the group with 16+ years of education, the model predicts correctly a first (1965-1985) rising and then (1985-2013) falling leisure share. However, the predicted changes for this group are smaller than in the data. ${ }^{31}$ Also, the predicted divergence in home hours across education groups is larger than in the data (see Figure O.6 in the "Online Appendix").

Similar to the results on leisure, the model also does a decent job in predicting the group-specific trends in hours worked. The theory predicts a significant acceleration in the fall in the market hours share from 1965-1985 to 1985-2013 as seen in the data for the groups with the least education. The model also predicts a significant increase in the market share for the group with 16+ years of education 1985-2013 (7.1 ppt vs. 6.0 ppt in the data), whereas the theory fails to account for the falling market hours of this group in the first subperiod of the sample.

The predictions for the four education groups can be aggregated using the weights in the time use data to generate the trends in leisure, market and home at the aggregate level. ${ }^{32}$ The model predicts the trend in aggregate leisure very well. Its share increases from 0.35 in 1965 to 0.37 in 1985 and then to 0.43 by 2013; whereas in the data it increases to 0.39 in 1985 and to 0.42 in 2013 . The theory also predicts the moderate overall decline in aggregate market share during 1965-2013 from 0.41 to 0.39 (it declines to 0.37 in the data). However, it slightly misses the timing as the decline starts after 1985, whereas in the data the decline was earlier. Finally, the model predicts a monotonic decline in aggregate home share during the entire period whereas in the data it has flatten out since the 1990s.

\footnotetext{
${ }^{30}$ Figure 0.7 in the "Online Appendix" summarize the quantitative results in an even simpler form: There we aggregate the four groups into two groups using the average weights in time use surveys: the less-educated (those with less than or equal to 12 years of education) and the more-educated (those with 13 or more years of education).

31 This result hinges on the evolution of the wages for this high-skilled group and is not very sensitive to the choices of the elasticity parameters $\sigma$ and $\varepsilon$.

32 The average weights of the four groups are $(0.15,0.34,0.23,0.28)$ in the sample of time use surveys and $(0.16,0.36,0.22,0.26)$ in the CPS sample.
} 


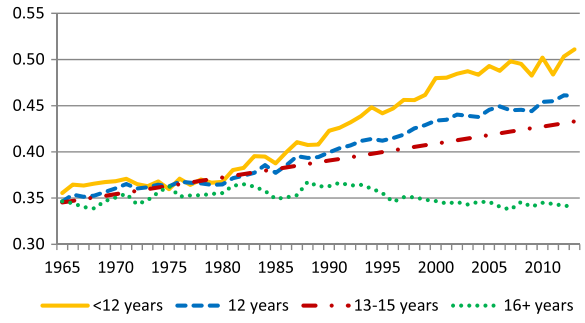

(a) Model Leisure share

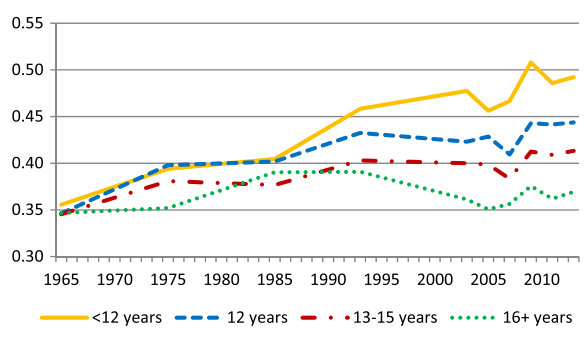

(b) Data Leisure share

Fig. 5 Leisure share by education group, model and data. Notes: The figure plots leisure shares predicted by the model and in the data 1965-2013 for four education groups. The leisure "share" is defined as: leisure hours/(leisure hours + home hours + market hours)

Table 2 Model versus data

\begin{tabular}{|c|c|c|c|c|}
\hline & $<12$ years & 12 years & $13-15$ years & $16+$ years \\
\hline \multicolumn{5}{|c|}{ Changes in leisure hours share } \\
\hline \multicolumn{5}{|l|}{$1965-85$} \\
\hline Model & 4.2 & 3.8 & 3.6 & 0.8 \\
\hline Data & 4.9 & 5.6 & 3.1 & 4.4 \\
\hline \multicolumn{5}{|c|}{$1985-2010$} \\
\hline Model & 9.6 & 6.8 & 4.6 & -1.1 \\
\hline Data & 9.2 & 4.0 & 3.4 & -2.2 \\
\hline \multicolumn{5}{|c|}{ Changes in market hours share } \\
\hline \multicolumn{5}{|l|}{$1965-85$} \\
\hline Model & -1.9 & -1.3 & -1.0 & 4.1 \\
\hline Data & -3.6 & -4.7 & -2.6 & -4.3 \\
\hline \multicolumn{5}{|c|}{$1985-2010$} \\
\hline Model & -9.6 & -5.0 & -1.4 & 7.1 \\
\hline Data & -7.3 & -1.0 & 0.3 & 6.0 \\
\hline
\end{tabular}

The table reports the changes in share of time allocate to leisure and market activities in percentage points. The "share" of an activity is expressed as relative to the total time, e.g., in the case of leisure: leisure share $=$ leisure hours/(leisure hours + home hours + market hours). For model: 1985 is the average of 1983-87 and 2010 is the average of 2008-2012. For data: 2010 is the average of 2009 and 2011

Instead of being only specified over consumption, the period utility function takes home production and leisure into account too. This has important implications for the welfare effects of changes in labor efficiency $e_{i}$. In indirect form, the period utility reads $\log \left(c_{i}\right)-\log \left(P_{i}\right)$, where $c_{i}$ is total (implicit) consumption expenditure and

$$
P_{i}=\left[\omega_{i}^{\epsilon}\left(\psi^{\sigma}+(1-\psi)^{\sigma} p_{h, i}^{1-\sigma}\right)^{\frac{1-\epsilon}{1-\sigma}}+\left(1-\omega_{i}\right)^{\epsilon} p_{z, i}^{1-\epsilon}\right]^{\frac{1}{1-\epsilon}},
$$

is a homothetic price index. Here the implicit prices $p_{h, i}$ and $p_{z, i}$ are proportionally increasing in $e_{i}^{1-\alpha}$. For simplicity, let's abstract from capital income and savings such that we have $c_{i}=\bar{w} e_{i} l$. If the period utility function only depends on consumption, i.e., with $\psi=\omega_{i}=1$, 
$P_{i}$ is independent of $e_{i}$ and a one percent increase in $e_{i}$ has the same welfare consequences as increasing $c_{i}$ by one percent. With valued home production and leisure this is no longer the case. Locally, Hulten's logic applies and $P_{i}$ increases by $(1-\alpha)\left(x_{z, i}+x_{h, i}\right)$ percent as $e_{i}$ increases by one percent. Our calibration implies that in the case of the group with $<12$ years of education in $1965 P_{i}$ increases by $(1-0.3)(0.36+0.26) \approx 0.43$ as labor efficiency $e_{i}$ increases by one percent. The welfare effect of an increase in $e_{i}$ is then $43 \%$ lower than the one of an increase in $c_{i}$. The reason for this effect is that labor efficiency only raises productivity in the market place, whereas leisure and home production is also valued.

So overall the model does a good job in accounting for the rising leisure inequality and aggregate trend in leisure. It performs less well in disentangling the trend in nonleisure hours into market and home; and for the time allocation of 16+ group. There are two additional observations to make. First, Bridgman (2016a) documents a significant decline in the labor-augmenting productivity growth for the home sector from about $2.5 \%$ before 1980 to zero growth afterward. Qualitatively, this can help to lower the predicted market share prior to 1980 bringing it closer to the data and it may also help to fix the timing of the increase in leisure inequality predicted by the model. Quantitatively, the effects are small, as shown in Appendix Figure O.8. The other predictions on market and home shares are also similar. Second, regarding the poor predictions for the $16+$ group, recall that the model assumes full anticipation of the fast relative wage growth post-1985. If the rise in college-premium was in reality not fully anticipated, this could reconcile why the rise in market hours and fall in leisure hours observed in the data are less than the model's predictions. Modeling expectations, however, is beyond the scope of our paper.

\section{Conclusion}

Market efficiency, initial capital and time are the primitives that ultimate constrain the behavior of households. While the former two are most likely subject to some form of exogenous distributions, time constraint is the same for all individual. Thus, being able to freely allocate one's time is an important tool for the "less-privileged" household to partly "reverse" the welfare inequality induced by the two exogenous inequalities in market efficiency and initial capital. This is indeed what is observed in the data where the less-educated allocating more time to leisure while more-educated allocating more time to market hours and obtain higher market income. Consistent with the empirical findings of Aguiar and Hurst (2007a) and Attanasio et al. (2015), the increase in leisure inequality has partly offset the welfare effects of the rising income and consumption inequality. This is done through both the direct channel of higher leisure time for the less-educated (low market efficiency individuals) and the equilibrium channel where the more-educated (high market efficiency individuals) work more in the market which increases the aggregate market production. One interesting application of the welfare effects implied by our model would be to study the effect of regulations on working hours in all sectors of the economy. 


\section{Appendix 1}

\section{Solving the household and firm problem}

Replacing $c_{z, i}$ and $c_{h, i}$ and in the utility function by (5) and (6) allows us to write the Lagrangian of the household problem as

$$
\begin{aligned}
\mathcal{L}_{i}= & \sum_{t=0}^{\infty} \beta^{t} u\left(c_{m, i}(t), k_{h, i}(t)^{\alpha}\left[A_{h}(t) l_{h, i}(t)\right]^{1-\alpha}, k_{z, i}(t)^{\alpha} l_{z, i}(t)^{1-\alpha}\right) \\
& +\sum_{t=0}^{\infty} \beta^{t} \lambda_{i}(t)\left[R(t)\left[a_{i}(t)-k_{h, i}(t)-k_{z, i}(t)\right]+a_{i}(t)[1-\delta]+\left[1-l_{h, i}(t)-l_{z, i}(t)\right] w_{i}(t)-c_{m, i}(t)\right]
\end{aligned}
$$

The first-order conditions are then given by

$$
\begin{aligned}
& \lambda_{i}(t)=\beta \lambda_{i}(t+1)[1+R(t+1)-\delta], \\
& \frac{\omega_{i} \psi\left[\psi c_{m, i}(t)^{\frac{\sigma-1}{\sigma}}+(1-\psi) c_{h, i}(t)^{\frac{\sigma-1}{\sigma}}\right]^{\frac{\sigma(\varepsilon-1)}{(\sigma-1) \varepsilon}-1} c_{m, i}(t)^{\frac{\sigma-1}{\sigma}}}{\omega_{i}\left[\psi c_{m, i}(t)^{\frac{\sigma-1}{\sigma}}+(1-\psi) c_{h, i}(t)^{\frac{\sigma-1}{\sigma}}\right]^{\frac{\sigma(\varepsilon-1)}{(\sigma-1) \varepsilon}}+\left(1-\omega_{i}\right) c_{z, i}(t)^{\frac{\varepsilon-1}{\varepsilon}}}=\lambda_{i}(t) c_{m, i}(t), \\
& \frac{\alpha \omega_{i}(1-\psi)\left[\psi c_{m, i}(t)^{\frac{\sigma-1}{\sigma}}+(1-\psi) c_{h, i}(t)^{\frac{\sigma-1}{\sigma}}\right]^{\frac{\sigma(\varepsilon-1)}{\sigma-1) \varepsilon}-1} c_{h, i}(t)^{\frac{\sigma-1}{\sigma}}}{\omega_{i}\left[\psi c_{m, i}(t)^{\frac{\sigma-1}{\sigma}}+(1-\psi) c_{h, i}(t)^{\frac{\sigma-1}{\sigma}}\right]^{\frac{\sigma(\varepsilon-1)}{(\sigma-1) \varepsilon}}+\left(1-\omega_{i}\right) c_{z, i}(t)^{\frac{\varepsilon-1}{\varepsilon}}}=\lambda_{i}(t) R(t) k_{h, i}(t),
\end{aligned}
$$

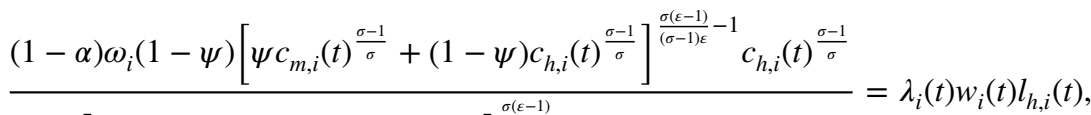

$$
\begin{aligned}
& \omega_{i}\left[\psi c_{m, i}(t)^{\frac{\sigma-1}{\sigma}}+(1-\psi) c_{h, i}(t)^{\frac{\sigma-1}{\sigma}}\right]^{\frac{\sigma(\varepsilon-1)}{\sigma-1) \varepsilon}}+\left(1-\omega_{i}\right) c_{z, i}(t)^{\frac{\varepsilon-1}{\varepsilon}} \\
& \frac{\alpha\left(1-\omega_{i}\right) c_{z, i}(t)^{\frac{\varepsilon-1}{\varepsilon}}}{\omega_{i}\left[\psi c_{m, i}(t)^{\frac{\sigma-1}{\sigma}}+(1-\psi) c_{h, i}(t)^{\frac{\sigma-1}{\sigma}}\right]^{\frac{\sigma(\varepsilon-1)}{(\sigma-1) \varepsilon}}+\left(1-\omega_{i}\right) c_{z, i}(t)^{\frac{\varepsilon-1}{\varepsilon}}}=\lambda_{i}(t) R(t) k_{z, i}(t), \\
& \frac{(1-\alpha)\left(1-\omega_{i}\right) c_{z, i}(t)^{\frac{\varepsilon-1}{\varepsilon}}}{\omega_{i}\left[\psi c_{m, i}(t)^{\frac{\sigma-1}{\sigma}}+(1-\psi) c_{h, i}(t)^{\frac{\sigma-1}{\sigma}}\right]^{\frac{\sigma(\varepsilon-1)}{(\sigma-1) \varepsilon}}+\left(1-\omega_{i}\right) c_{z, i}(t)^{\frac{\varepsilon-1}{\varepsilon}}}=\lambda_{i}(t) w_{i}(t) l_{z, i}(t) .
\end{aligned}
$$

The representative firm solves

$$
\max _{K_{m}(t), L_{m}(t)} K_{m}(t)^{\alpha}\left[A_{m}(t) L_{m}(t)\right]^{1-\alpha}-R(t) K_{m}(t)-\bar{w}(t) L_{m}(t) .
$$

The first-order conditions are 


$$
\begin{gathered}
\alpha\left[\frac{K_{m}(t)}{A_{m}(t) L_{m}(t)}\right]^{\alpha-1}=R(t), \\
(1-\alpha) A_{m}(t)\left[\frac{K_{m}(t)}{A_{m}(t) L_{m}(t)}\right]^{\alpha}=\bar{w}(t) .
\end{gathered}
$$

\section{Proof of Lemma 1}

Proof Combining the first-order conditions (A.3) and (A.4) as well as (A.5) and (A.6) gives

$$
\frac{k_{h, i}(t)}{l_{h, i}(t)}=\frac{k_{z, i}(t)}{l_{z, i}(t)}=\frac{e_{i}(t) \bar{w}(t)}{R(t)} \frac{\alpha}{1-\alpha}, \forall i .
$$

Using this together with the first-order conditions of the firm's problem, (A.9) and (A.8), and the market clearing conditions (9) and (10) (as well as (3)) gives

$$
\frac{K_{m}(t)}{L_{m}(t)}=\frac{\bar{w}(t)}{R(t)} \frac{\alpha}{1-\alpha}=\frac{K(t)}{L} .
$$

Using this fact in (A.9) and (A.8) gives (15) and (16). Finally, combining (A.10) and (A.11) gives (14).

\section{Proof of Lemma 4}

Proof By combining (A.2)-(A.4), (6) and (17) gives

$$
\frac{1-\psi}{\psi}\left(\frac{c_{m, i}(t)}{c_{h, i}(t)}\right)^{1 / \sigma}=p_{h, i}(t) .
$$

This equation has the interpretation that under optimal behavior the marginal rate of substitution between $m$ and $h$ has to equalize their implicit relative price. Let $c_{m h, i}(t) \equiv\left[\psi c_{m, i}(t)^{\frac{\sigma-1}{\sigma}}+(1-\psi) c_{h, i}(t)^{\frac{\sigma-1}{\sigma}}\right]^{\frac{\sigma}{\sigma-1}}$ be the consumption of the composite non-leisure good. Given the definition of implicit price for non-leisure good, $\tilde{p}_{m h, i}(t)=\left[\psi^{\sigma}+(1-\psi)^{\sigma} p_{h, i}(t)^{1-\sigma}\right]^{\frac{1}{1-\sigma}}$, and (A.12) we have

$$
\tilde{p}_{m h, i}(t) c_{m h, i}(t)=c_{m, i}(t)+p_{h, i}(t) c_{h, i}(t) .
$$

Note that we also have

$$
\frac{p_{h, i}(t) c_{h, i}(t)}{\tilde{p}_{m h, i}(t) c_{m h, i}(t)}=\frac{1}{1+\left(\frac{\psi}{1-\psi}\right)^{\sigma} p_{h, i}(t)^{\sigma-1}}
$$

and 


$$
\frac{c_{m, i}(t)}{\tilde{p}_{m h, i}(t) c_{m h, i}(t)}=\frac{1}{1+\left(\frac{\psi}{1-\psi}\right)^{-\sigma} p_{h, i}(t)^{1-\sigma}} .
$$

Equating the marginal rate of substitution across $c_{m h, i}(i)$ and $c_{z, i}(i)$, ob by combining (A.13) with (A.5) and (A.6), we obtain the relative expenditure

$$
\frac{\tilde{p}_{m h, i}(t) c_{m h, i}(t)}{p_{z, i}(t) c_{z, i}(t)}=\left(\frac{\omega_{i}}{1-\omega_{i}}\right)^{\varepsilon}\left(\frac{p_{z, i}(t)}{\tilde{p}_{m h, i}(t)}\right)^{\varepsilon-1} .
$$

Combining (A.13) with (24) and (A.16) and

$$
\frac{\tilde{p}_{m h, i}(t) c_{m h, i}(t)}{c_{i}(t)}=\frac{1}{1+\left(\frac{\omega_{i}}{1-\omega_{i}}\right)^{-\varepsilon}\left(\frac{p_{z, i}(t)}{\tilde{p}_{m h, i}(t)}\right)^{1-\varepsilon}} .
$$

Finally, (A.17) together with (A.14) and (A.15) yield (25) and (26).

\section{Proof of Lemma 6}

Proof Using the definition of $c_{i}(t)$ it the budged constraint (4) gives (30). By summing the first-order conditions (A.2)-(A.6) we obtain

$$
c_{i}(t)=\frac{1}{\lambda_{i}(t)} .
$$

Combining this with the first-order condition (A.1) gives (31).

\section{Proof of Proposition 2}

Proof With $\tilde{k}(t)=\tilde{k}^{\star}$ we have $\frac{\int_{0}^{1} c_{i}(t+1) d i}{\int_{0}^{1} c_{i}(t) d i}=\frac{\int_{0}^{1} a_{i}(t+1) d i}{\int_{0}^{1} a_{i}(t) d i}=\gamma_{m}, \forall i$ and the transversality conditions are fulfilled. To see global saddle path stability, note that the system (30), (31), (15) and (16) is identical to the one of a one sector neoclassical growth model with CobbDouglas production and logarithmic instantaneous utility over $c_{i}(t)$.

\section{Proof of Lemma 7}

Proof The budget constraint (4) can be written as (see (12) and (13)) 


$$
a_{i}(t+1)=[1+R(t)-\delta] a_{i}(t)+\bar{w}(t) e_{i}(t) \bar{l}-c_{i}(t) .
$$

Consolidating these budget constraints over time and using the transversality condition gives

$$
\begin{aligned}
c_{i}(0)+\sum_{t=1}^{\infty} c_{i}(t) \prod_{s=1}^{t} \frac{1}{1+R(s)-\delta}= & (1+R(0)-\delta) a_{i}(0) \\
& +\bar{w}(0) e_{i}(0) \bar{l}+\sum_{t=1}^{\infty} \bar{w} e_{i}(t) \bar{l} \prod_{s=1}^{t} \frac{1}{1+R(s)-\delta} .
\end{aligned}
$$

Substituting in the factor prices along the balanced growth path gives (36).

Supplementary Information The online version contains supplementary material available at https://doi. org/10.1007/s10887-021-09189-8.

Acknowledgements We thank Josep Pijoan-Mas, Markus Poschke and Valerie Ramey for excellent discussions and Orhun Sevinc valuable comments and his help with the data. We thank Dirk Krueger, Chris Pissarides, Marla Ripoll, Richard Rogerson, Kjetil Storesletten, and Erin Wolcott, as well as seminar participants at HKUST and LSE; and conference participants at Micro Macro Labor Economics Conference, 2017 at FRB SF, Asian Meeting of the Econometric Society 2017, Conference on Macro Development and Structural Change at Madrid 2016, ESSIM-CEPR 2016, SED 2016 and the Workshop on Structural Transformation at ASU 2016 for helpful comments. Timo Boppart thanks Vetenskaprådet (Grant 2016-02194) for financial support. Rachel Ngai acknowledges support from CfM and hospitality from the Institute of Advanced Studies at HKUST.

Funding Open access funding provided by Stockholm University.

Open Access This article is licensed under a Creative Commons Attribution 4.0 International License, which permits use, sharing, adaptation, distribution and reproduction in any medium or format, as long as you give appropriate credit to the original author(s) and the source, provide a link to the Creative Commons licence, and indicate if changes were made. The images or other third party material in this article are included in the article's Creative Commons licence, unless indicated otherwise in a credit line to the material. If material is not included in the article's Creative Commons licence and your intended use is not permitted by statutory regulation or exceeds the permitted use, you will need to obtain permission directly from the copyright holder. To view a copy of this licence, visit http://creativecommons.org/licenses/by/4.0/.

\section{References}

Aguiar, M., Bils, M., Charles, K. K., \& Hurst, E. (2017). Leisure luxuries and the labor supply of young men. Working paper, Princeton University.

Aguiar, M., \& Hurst, E. (2007a). Measuring trends in leisure: The allocation of time over five decades. Quarterly Journal of Economics, 122, 969-1006.

Aguiar, M., \& Hurst, E. (2007b). Lifecycle prices and production. American Economic Review, 97, $1533-1559$. 
Aguiar, M., \& Hurst, E. (2009). The increase in leisure inequality: 1965-2005. American Enterprise Institute for Public Policy Research.

Aguiar, M., Hurst, E., \& Karabarbounis, L. (2012). Recent developments in the economics of time use. Annual Review of Economics, 4, 373-397.

Attanasio, O., Hurst, E., \& Pistaferri, L. (2015). The evolution of income, consumption, and leisure inequality in the U.S. In C. Carroll, T. Crossley, \& J. Sabelhaus (Eds.), Improving the measurement of consumer expenditures (pp. 1980-2010). University of Chicago Press.

Bick, A., Fuchs-Schuendeln, N., \& Lagakos, D. (2018). How do hours worked vary with income? Crosscountry evidence and implications. American Economic Review, 108(1), 170-99.

Blundell, R., \& Walker, I. (1982). Modeling the joint determination of household labor supplies and commodities demand. Economic Journal, 92, 351-364.

Boerma, J., \& Karabarbounis, L. (2017). Inferring inequality with home production. NBER Working paper No. 24166.

Boerma, J., \& Karabarbounis, L. L. (2020). Labor market trends and the changing value of time. Journal of Economic Dynamics and Control, 115, 103885.

Boppart, T., \& Krusell, P. (2020). Labor supply in the past, present, and future: A balanced growth perspective. Journal of Political Economy, 128(1), 118-157.

Boppart, T., Krusell, P., \& Olsson, J. K. (2017). Labor supply in the past, present, and future: Who and how much?. Stockholm University.

Bridgman, B. (2016a). Home productivity. Journal of Economic Dynamics and Control, 71, 60-76.

Bridgman, B. (2016b). Engines of leisure. Working paper, Bureau of Economic Analysis.

Caselli, F., \& Ventura, J. (2000). A representative consumer theory of distribution. American Economic Review, 90(4), 909-926.

Cooley, T. F., \& Prescott, E. C. (1995). Economic growth and business cycles. Frontiers of Business Cycle Research, 39(64), 1-38.

Costa, D. (2000). The wage and the length of the work day: From the 1890s to 1991. Journal of Labor Economics, XVIII, 156-181.

Elsby, M. W., \& Shapiro, M. D. (2012). Why does trend growth affect equilibrium employment? A new explanation of an old puzzle. American Economic Review, 102(4), 1378-1413.

Fang, L., Hannusch, A., \& Silos, P. (2020). Bundling time and goods: Implications for hours dispersion. mimeo.

Fang, L., \& Zhu, G. (2017). Time allocation and home production technology. Journal of Economic Dynamics and Control, 78, 88-101.

Freeman, R. B., \& Schettkat, R. (2005). Marketization of household production and the EU-US gap in work. Economic Policy, 20(41), 6-50.

Gelber, A., \& Mitchell, J. W. (2012). Taxes and time allocation: Evidence from single women and men. The Review of Economic Studies, 79, 863-897.

Gimenez-Nadal, J. I., \& Sevilla, A. (2012). Trends in time allocation: A cross-country analysis. European Economic Review, 56(22), 1338-1359.

Ham, J., \& Reilly, K. (2002). Testing intertemporal substitution, implicit contracts, and hours restriction models of labor market using micro data. American Economic Review, 92(4), 905-927.

Katz, L. F., \& Murphy, K. M. (1992). Changes in relative wages, 1963-1987: Supply and demand factors. Quarterly Journal of Economics, 107(1), 35-78.

Kopecky, K. (2011). The trend in retirement. International Economic Review, 52(2), 287-316.

Lucas, R. E, Jr., \& Rapping, L. A. (1969). Real wages, employment, and inflation. Journal of Political Economy, 77(5), 721-54.

Mazzolari, F., \& Ragusa, G. (2013). Spillovers from high-skill consumption to low-skill labor markets. The Review of Economics and Statistics, 95(1), 74-86.

Michelacci, C., \& Pijoan-Mas, J. (2016). Labor supply with job assignment under balanced growth. Journal of Economic Theory, 163, 110-140.

Ngai, L. R., \& Pissarides, C. A. (2007). Structural change in a multisector model of growth. American Economic Review, 97, 429-443.

Ngai, L. R., \& Pissarides, C. A. (2008). Trends in hours and economic growth. Review of Economic Dynamics, 3, 1-26.

Rachel, L. (2019). Leisure-enhancing technological change. mimeo.

Ramey, G., \& Ramey, V. (2010). The rug race. Brookings Papers on Economic Activity, (1), 129-176.

Ramey, V. A. (2007). How much has leisure really increased since 1965? University of California at San Diego Working paper.

Ramey, V. A., \& Francis, N. (2009). A century of work and leisure. American Economic Journal: Macroeconomics, 1, 189-224. 
Rupert, P., Rogerson, R., \& Wright, R. (1995). Estimating substitution elasticities in household production models. Economic Theory, 6, 179-193.

Vandenbroucke, G. (2009). Trends in hours: The U.S. from 1900 to 1950. Journal of Economic Dynamics and Control, 33(1), 237-249.

Winston, C. G. (1966). An international comparison of income and hours of work. The Review of Economics and Statistics, 48(1), 28-39.

Wolcott, E. (2021). Employment inequality: Why do the low-skilled work less now? Journal of Monetary Economics, 118, 161-177.

Publisher's Note Springer Nature remains neutral with regard to jurisdictional claims in published maps and institutional affiliations. 